\title{
Coyo Oriente. Referente del Período Medio en San Pedro de Atacama
}

\section{Coyo Oriente. Prototype of San Pedro de Atacama's Middle Period}

\author{
Agustín Llagostera Martínez ${ }^{1}$ https://orcid.org/0000-0002-9502-8350 \\ María Antonietta Costa-Junqueira ${ }^{2}$ https://orcid.org/0000-0001-7280-7063 \\ ${ }^{1}$ Instituto de Investigaciones Antropológicas de la Universidad de Antofagasta, Antofagasta, \\ CHILE. Email: allagostera@vtr.net \\ ${ }^{2}$ Arquéologa y bioantropóloga, Antofagasta, CHILE. Email: ma.costa@vtr.net
}

\begin{abstract}
Resumen
El cementerio arqueológico de Coyo Oriente fue utilizado por Tarragó (1968, 1989) como prototipo para definir el Período Medio de la Etapa Agroalfarera de San Pedro de Atacama. Sin embargo, hasta el momento solo se han realizado análisis parciales y no se ha hecho una revisión detallada y completa del mencionado sitio. Por este motivo, hemos considerado importante desarrollar un análisis integral y una evaluación de sus contextos, con el fin de aportar mayor información para el conocimiento de un yacimiento considerado referente fundamental en la estructura de la secuencia cronológica de la Etapa Agroalfarera de San Pedro de Atacama.

Coyo Oriente es el segundo sitio con mayor número de objetos Tiwanaku de San Pedro de Atacama, a lo que se agrega también un importante componente de la Cultura Aguada del Noroeste Argentino (NOA). En este trabajo se discute el tema de la etnicidad y de la foraneidad. Se analizan los indicadores de estatus y su comportamiento a través del tiempo. La información relevada para este trabajo, complementada con información existente, nos ha permitido definir el Perfil Ergológico de este yacimiento, describiendo sus componentes contextuales y llevándolos a Indice de Representatividad, como referentes para las fases Coyo y Yaye.
\end{abstract}

Palabras claves: San Pedro de Atacama, Tiwanaku, periodificación, contextos funerarios.

\begin{abstract}
The archaeological cemetery of Coyo Oriente was used by Tarragó $(1968,1989)$ as prototype to define San Pedro de Atacama's Middle Period; nevertheless, thus far only partial analyses have been published and no detailed and thorough review of the site exists. For this reason, we considered important to conduct a comprehensive analysis and evaluation of these contexts and provide documented information about a site that is considered a fundamental reference in structuring the chronological sequence of the agroalfarero period of San Pedro de Atacama. Coyo Oriente has the second most Tiwanaku objects in San Pedro de Atacama, and also includes an important presence of Aguada material culture (NW Argentina). Here, we also discuss the issue of ethnicity and foreignness. Status indicators and their behavior over time are analyzed. The analysis of the surveyed information, supplemented with existing information enable us to define the Ergologic Profile of this site, describing its contextual components and relating them to their corresponding Index of Representativeness, projected for this site and as benchmarks for the Coyo and Yaye phases.
\end{abstract}

Keywords: San Pedro de Atacama, Tiwanaku, periodization, funerary contexts.

Recibido: 2 agosto 2017. Aceptado: 20 octubre 2019 


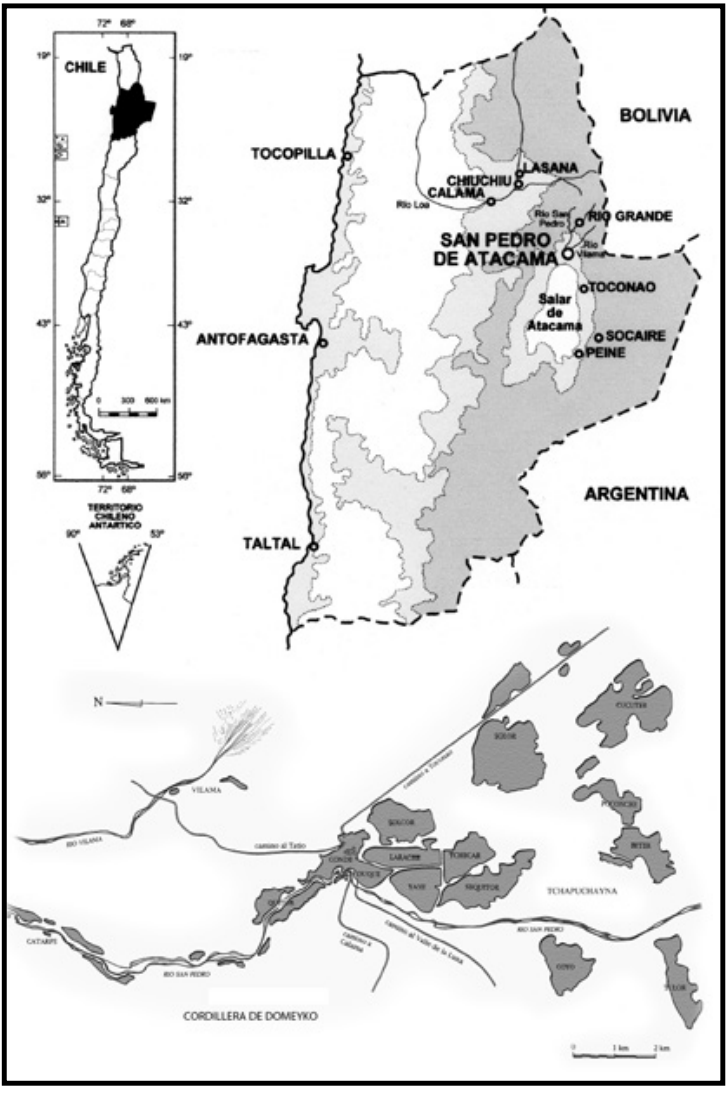

Figura 1. Mapa con la ubicación de San Pedro de Atacama y del distrito de Coyo en el cual se ubica el cementerio arqueológico de Coyo Oriente.

\section{Introducción}

El cementerio arqueológico de Coyo Oriente se ubica en el distrito (ayllu) de Coyo, en la localidad de San Pedro de Atacama, norte de Chile (Figura 1), habiéndose constituido en sitio-tipo para caracterizar el Período Medio de San Pedro de Atacama, el que fue consignado como "fase Coyo" para esta localidad (Tarragó, 1989).

Este cementerio fue excavado por Gustavo Le Paige y según sus referencias, las excavaciones entregaron 115 cuerpos en la parte norte y 178 en la zona sur, lo que da un total de 293 individuos, ubicados en 160 tumbas (Le Paige, 1972-73). Posterior a su publicación de 1972-73, Le Paige excavó la zona que, en sus apuntes de 1975, denominó "lado sur del cementerio", la cual nosotros hemos considerado como el extremo sur de la zona sur y la hemos denominado
Sector Sur-Sur. Para este sector se registran 43 nuevos enterratorios, con lo que el total ascendería a 203 tumbas.

Berenguer, Deza, Román y Llagostera (1986) utilizaron el concepto de sitio-tipo para denominar las fases de la periodificación que Tarragó elaboró para el Período Agroalfarero de San Pedro de Atacama (1968), de tal manera que, a la fase $\mathrm{V}$ de dicha autora se le asignó el nombre de "Coyo". Tarragó segregó la mencionada fase a partir de otros sitios y no precisamente de Coyo Oriente, debido a que este yacimiento fue excavado por Le Paige con posterioridad a la residencia de la investigadora en San Pedro; por lo cual, ella no tuvo acceso directo a los materiales del mencionado sitio. ${ }^{1}$ Basándose en aquellos otros sitios, Tarragó caracterizó dicha fase por la ocurrencia de un grupo de tumbas con San Pedro Negro Pulido en disminución, San Pedro Negro y Rojo Grabado, Gris Pulido Grueso y Tiwanaku Transformado. Posteriormente, en 1989, complementó la descripción señalando que la época Coyo abarcaría la segunda etapa, tal vez la más intensa por sus efectos, de la interacción entre la sociedad altiplánica de Tiwanaku y las comunidades de los oasis de Atacama. Con esto, Coyo Oriente pasó a convertirse en el referente del Período Medio en San Pedro de Atacama.

Diferentes autores han tocado tangencialmente este sitio, especialmente al abordar la problemática general de Tiwanaku en San Pedro de Atacama (Orellana, 1985; Llagostera, 1995 y 2006a; Uribe y Agüero, 2001; Torres-Rouff, 2011). Hasta el momento solo cuatro trabajos se han circunscrito específicamente a Coyo Oriente, aunque fueron enfocados en aspectos puntuales como es la textilería (Oakland, 1992) y la bioantropología (Costa, Llagostera y Cocilovo, 2008; Cocilovo, Varela y Llagostera, 2011; Costa y Llagostera, 2014).

1 Tarragó inicialmente denominó este segmento de su secuencia como Serie V (1968) y más tarde como Fase $\mathrm{V}$ (1976); posteriormente, Berenguer y colaboradores (1986) sugieren sustituir los números romanos por nombres de sitio-tipos, utilizando los sitios más representativos para designar cada una de las fases. A partir de entonces se adopta la denominación de Fase Coyo (Tarragó, 1989). 
Oakland (1992), utilizando los textiles de Coyo Oriente como indicador de etnicidad, distingue dos estilos textiles distintos, lo que le sugiere un uso multiétnico del cementerio. Uno de los grupos estaría más ampliamente distribuido en San Pedro de Atacama; el otro, en cambio, estaría más específicamente asociado con el oasis de Coyo, teniendo textiles y artefactos con iconografía Tiwanaku. Este resultado le sugiere que un grupo representa el estilo y grupo étnico local y el otro, un grupo étnico diferente relacionado estrechamente con Tiwanaku.

Lessa y Mendonca de Souza (2006), en una muestra de cráneos de Coyo Oriente, analizaron signos de traumas asociados a violencia determinando, por las características de las lesiones, que las heridas en los varones (12\%) fueron infligidas durante luchas rituales, en tanto que, en las mujeres $(9,9 \%)$ estas fueron resultado de conflictos domésticos.

Costa et al. (2008) enfocaron su análisis fundamentalmente en la deformación craneana contrastada con los atributos de sexo y edad y, a su vez, analizaron el comportamiento de estos tres parámetros a través de las zonas que fueron diferenciadas por Le Paige para el sitio. Además se contrastaron los resultados con los grupos segregados por Oakland en función de los textiles.

Cocilovo et al. $(1994,2011)$ han llevado a cabo evaluaciones del dimorfismo sexual, de la variación etaria y de la deformación artificial del cráneo, contrastando estos rasgos con elementos culturales como textiles y tabletas para alucinógenos y, a su vez, confrontándolos con las zonas del cementerio.

Por su parte, Costa y Llagostera (2014) se concentraron en el estudio de cuatro casos afectados por la enfermedad Leishmaniasis, analizando los elementos biológicos y culturales asociados con ellos, así como el contexto bioantropológico y cultural en que estos individuos se encontraban insertos. Dado que el insecto vector de esta enfermedad nunca estuvo presente en San Pedro de Atacama, se postula que estas personas serían originarias de alguna zona transandina.

En consecuencia, hasta el momento solo se han realizado análisis parciales y no se ha hecho una revisión detallada y completa del contexto del sitio, por lo cual hemos considerado importante llevar a cabo una evaluación de sus contextos y un análisis integral del cementerio, de tal manera de poder definir el Perfil Ergológico de este yacimiento, describiendo sus componentes contextuales y llevándolos a su correspondiente Índice de Representatividad (IR), definido este como el porcentaje de objetos, individuos o tumbas en relación al total de ejemplares de su categoría, ya sea en el sector, en la fase o en el subuniverso de análisis, permitiendo una valorización relativa y comparativa entre sus congéneres. Con ello se busca aportar mayor información para un conocimiento más detallado de un yacimiento considerado como referente fundamental en la estructura de la secuencia del Período Agroalfarero de San Pedro de Atacama, especialmente referido al Período Medio.

\section{Espacio y tiempo}

Le Paige (1972-73) señala que una parte del cementerio de Coyo Oriente se ubicaba al interior de un potrero (zona norte) y otra, al exterior de este (zona sur) y -agrega-, que el cerco que pasa entre estas dos zonas está ubicado en un área casi sin tumbas. Con esto es claro que entre la zona Sur y la zona Norte existe una separación física que testifica una inflexión importante en la secuencia sociocultural; en cambio entre la zona Sur y la zona Sur-Sur no existe separación ya que se trata de un continuo que devela que los colonizadores del sitio inhumaron inicialmente a sus muertos a partir del extremo sur y desde allí fueron estructurando el espacio funerario en dirección norte; avance que, a su vez, refleja un progresivo y cada vez mayor posicionamiento en el distrito.

Le Paige ya había inferido que esta disgregación espacial tenía su correspondencia en la secuencia temporal al señalar que 58 tumbas serían asignables a los períodos II y III de San Pedro de Atacama; las demás, especialmente las ubicadas en la zona norte, corresponderían al período IV.

Las primeras dataciones para Coyo Oriente fueron suministradas por Oakland, a través de fechas radiocarbónicas que van desde 639 a 910 DC (Oakland, 1992), las que sectorialmente se distribuyen de la 
siguiente manera: sector Sur-Sur: 672 DC y 888 DC; sector Sur: 639 DC, 677 DC y 910 DC; sector Norte: 677 DC (Tabla 1).

Nosotros hemos querido dilucidar la secuencia cronológica a través de nuevas dataciones para los tres sectores del cementerio: para el sector Sur-Sur se obtuvo una fecha de 720 DC, para el sector Sur dos fechas de 900 y 1.080 DC y para el sector Norte dos de 1.085 y 1.230 DC (Tabla 2).

Independiente de los desajustes que se observan entre las fechas $\mathrm{C} 14$, especialmente en relación a lo temprano de la datación Norte y al desfase de las fechas TL en relación a las primeras, en general, el set de fechas apuntaría a una secuencia que avanza en el tiempo de sur a norte, respaldando lo que Le Paige había inferido a partir de los contextos.

\section{Análisis contextual}

\section{Alfarería}

Dado que Le Paige marcó cada pieza cerámica con el número correspondiente a su tumba, y basándonos en sus apuntes de terreno, ha sido posible recomponer los contextos alfareros en relación a las unidades funerarias de este cementerio, realizando pre- viamente una minuciosa depuración de la colección con el fin de validar la muestra que se dispondrá para el objetivo propuesto.

De acuerdo a los atributos morfológicos de las piezas alfareras, se pudo diferenciar siete tipos, siendo condición primordial que cada uno de ellos incorpore más de un ejemplar con similares atributos. En los casos en que aparece solo un ejemplar, este ha sido considerado como atípico, sin base para estructurar un tipo.

Para la descripción de los tipos nos ajustamos lo mejor posible a la nomenclatura y formatos elaborados por Tarragó (1989), para, de esta manera, evitar crear mayor complejidad en la taxonomía. En los casos pertinentes se señala las correspondencias o similitudes e incluso se indica las figuras que en el texto de la autora ilustran las formas referidas.

Tipo 1 (Figura 2a). Vasijas cerradas, ovoides, base convexa sin diferenciación del cuerpo, borde diferenciado (Tarragó: NPVIIc, figs 13.1 y 13.4) (Uribe, Santana-Sagredo, Maturana, Flores y Agüero, 2016: Figura 3d, e y f).

Tipo 2 (Figura 2b). Vasijas troncocónicas invertidas (acampanadas), levemente más altas que el ancho

Tabla 1. Fechas radiocarbónicas obtenidas por Oakland (1992).

\begin{tabular}{|c|c|c|c|c|}
\hline Sector/tumba & Laboratory & Radiocarbon Years & Calibrated Years & Material \\
\hline Sur (5383) & Beta-33858 & $1430 \pm 60 \mathrm{BP}$ & $\mathrm{AD} 639 \pm 20$ & textiles \\
\hline Sur-Sur (5341) & Beta-33856 & $1320 \pm 60 \mathrm{BP}$ & $\mathrm{AD} 672 \pm 60$ & textiles \\
\hline Norte (4064) & Beta-33855 & $1310_{ \pm} 80 \mathrm{BP}$ & $\mathrm{AD} 677 \pm 80$ & Bone, muscle \\
\hline Sur (4012) & Beta-33853 & $1310 \pm 70 \mathrm{BP}$ & $\mathrm{AD} 677 \pm 50$ & bone \\
\hline Sur-Sur (5347) & Beta-33857 & $1155 \pm 80 \mathrm{BP}$ & AD $888_{ \pm}+100$ & textiles \\
\hline Sur (4026) & Beta-33854 & $1100 \pm 70 \mathrm{BP}$ & AD $910 \pm 90$ & Muscle, skin \\
\hline
\end{tabular}

Tabla 2. Fechas por termoluminiscencia obtenidas para los sectores del cementerio de Coyo Oriente.

\begin{tabular}{|l|c|c|c|c|c|c|}
\hline Muestra & Tumba & Sector & P(gy) & D(gy/ańo) & Edad ( ap) & Fecha \\
\hline UCTL 1489 & 4174 & Norte & $3.40_{ \pm} 0.19$ & $4,40^{*} 10^{-3}$ & $770_{ \pm} 80$ & 1230 DC \\
\hline UCTL 1488 & 4049 & Norte & $5,50 \pm 0,50$ & $6,00^{*} 10^{-3}$ & $915_{ \pm} 100$ & 1085 DC \\
\hline UCTL 1486 & 3994 & Sur & $5,10_{ \pm} 0,21$ & $5,54^{*} 10^{-3}$ & $920_{ \pm} 100$ & 1080 DC \\
\hline UCTL 1487 & 4044 & Sur & $5,56_{ \pm} 0,45$ & $5,09^{*} 10^{-3}$ & $1100_{ \pm} 100$ & 900 DC \\
\hline UCTL 1490 & 5371 & Sur-Sur & $5,40_{ \pm} 0,40$ & $4,22^{*} 10^{-3}$ & $1280_{ \pm} 130$ & 720 DC \\
\hline
\end{tabular}


promedio, de base convexa o plana. En relación a la decoración distinguimos tres variedades: variedad $A$, sin decoración; variedad $B$, una mitad rojo y la otra negra con divisoria vertical; variedad C, decoración grabada (Uribe et al., 2016: Figura 3c; Tarragó: Figura 17.2).

Tipo 3 (Figura 2c). Vasijas troncocónicas invertidas con ancho mayor que alto, base plana, perfil de la mitad superior de la pared levemente cóncavo separado de la mitad inferior por un ángulo suave. Siempre presentan decoración grabada (Tarragó: Figuras $17.1,4,5,6 ; 18.4)$.

Tipo 4 (Figura 2d y e). Vasijas abiertas de sección hemiesférica, base convexa (Tarragó: GALIS.Ivc, Figura 19.10).

Tipo 5 (Figura 2f). Escudillas bajas de sección hemiesférica o hemielíptica, base convexa (Tarragó: GPGIVc, Figura 19.3 y 19.4).
Tipo 6 (Figura 2g). Platos expandidos de base convexa (Tarragó: GPGIV, fig. 19.3). Algunos ejemplares pueden presentar pequeñas asas como prolongación del labio.

Tipo 7 (Figura 2h). Jarros troncocónicos invertidos o subcilíndricos de base plana o convexa, borde levemente evertido, con asa cintiforme vertical (Tarragó: GPGIpaV, Figura 57.4 y 57.6)

Tipo 0. Atípicos. Dentro de esta categoría se considera un kero negro con típica forma Tiwanaku, pero carente de la policromada decoración de aquellos kero; un trípode que puede provenir del sureste de Bolivia y otra diversidad de vasijas únicas o escasamente representadas para las cuales no tenemos referentes de procedencia.

En general, las cerámicas grabadas (tipos $2 \mathrm{C}$ y 3 ) son las que presentan la factura más cuidadosa del bagaje alfarero de Coyo Oriente, singularizándose
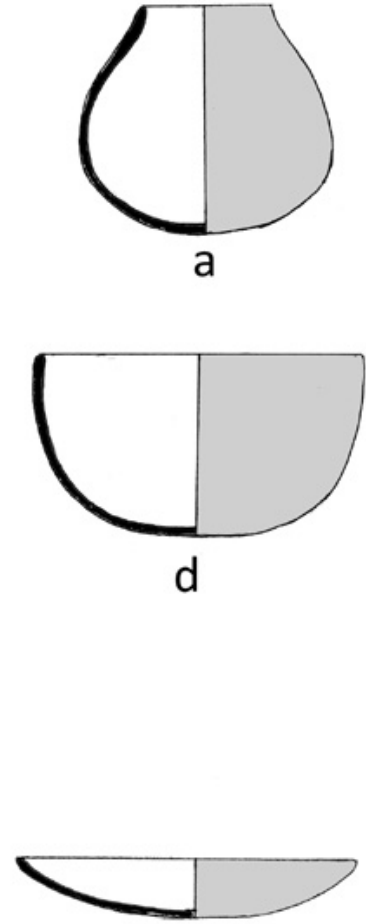

g
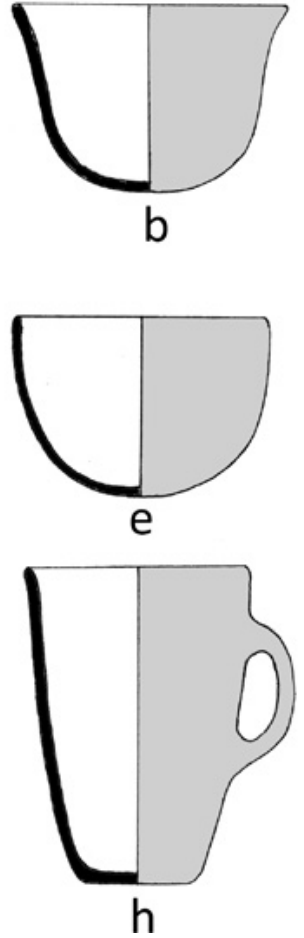
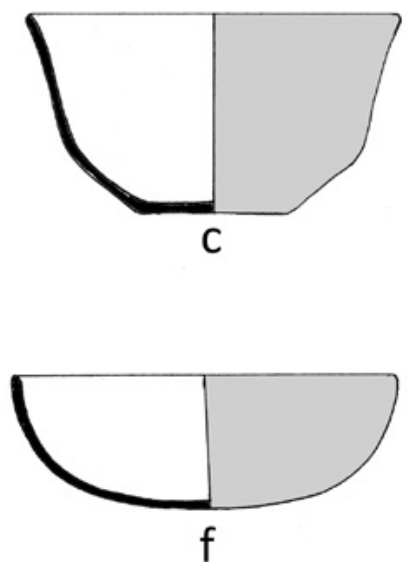

Figura 2. Tipología alfarera: (a) Tipo 1, (b) Tipo 2, (c) Tipo 3, (d y e) Tipo 4, (f) Tipo 5, (g) Tipo 6 y (h) Tipo 7. 


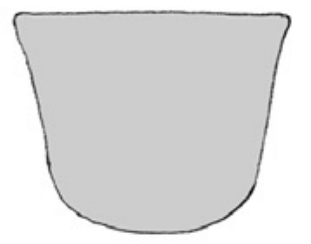

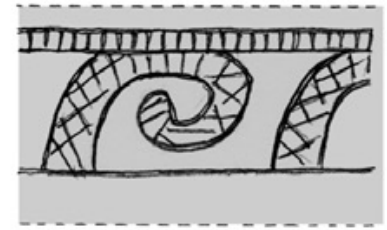

a

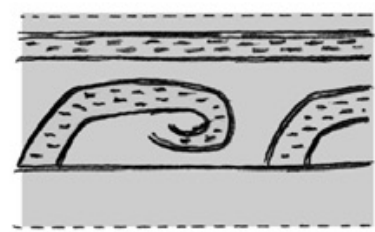

C

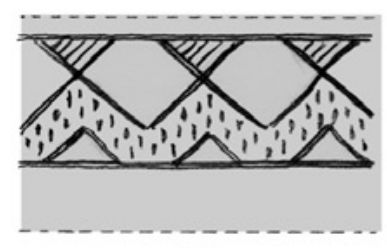

e

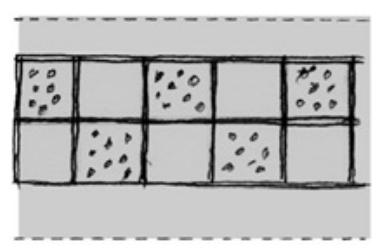

b

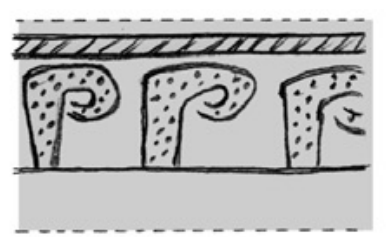

d
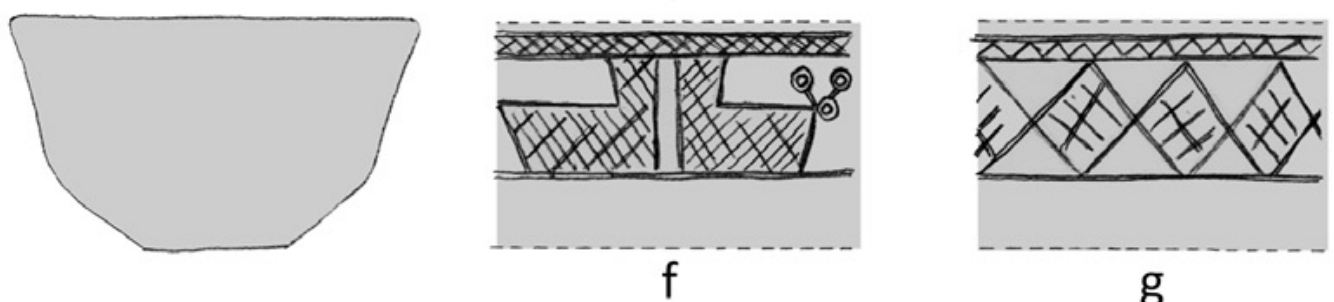

g
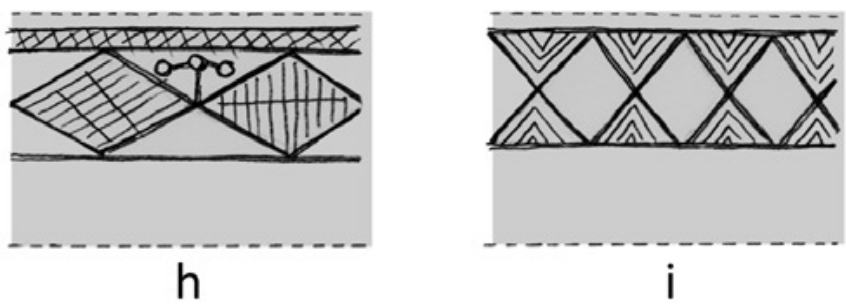

Figura 3. Alfarería grabada Tipo 2C: (a) 5369, (b) 4066, (c) 3974, (d) 4103, (e) 3953. Alfarería grabada Tipo 3: (f) 4196, (g) 4137, (h) 4196, (i) 3953. 
por su superficie finamente pulida a diferencia de las otras que han sido sindicadas como "casi pulidas" por su menor prolijidad (Figura 3).

\section{Asociaciones tipológicas}

Aplicando la tipología precedente se procedió a reconstruir las correspondientes asociaciones funerarias para cada una de las tumbas que portan alfarería en sus contextos. Solo fueron consideradas aquellas tumbas cuyos contextos daban seguridad en la identificación de sus componentes alfareros. Esto permitió disponer de una matriz de análisis comparativo aplicado al conjunto de tumbas, en la cual, para cada unidad funeraria se desplegó su contexto alfarero representando los tiestos por sus correspondientes tipos. Una vez que cada tumba tuvo definido su contexto tipológico, se procedió a segregar las tumbas de acuerdo a los tres sectores que conforman el sitio (Tablas 3, 4 y 5).

En cuanto a las asociaciones alfareras representativas por sectores, se obtuvo la siguiente distribución: en el sector Sur-Sur se registran 16 tumbas, las que se

Tabla 3. Asociaciones contextuales del sector Sur-Sur.

\begin{tabular}{|l|l|l|l|l|l|l|l|l|}
\hline Tumba & 1 & 2 & 3 & 4 & 5 & 6 & 7 & 0 \\
\hline $\mathbf{5 3 0 3 - 0 5}$ & & & & & $\mathrm{X}$ & & & \\
\hline $\mathbf{5 3 0 6}$ & & & & & $\mathrm{X}$ & & & \\
\hline $\mathbf{5 3 1 6}$ & & & & & $\mathrm{X}$ & & & \\
\hline $\mathbf{5 3 2 7 - 2 8}$ & & & & & $\mathrm{X}$ & & & \\
\hline $\mathbf{5 3 3 2}$ & & & & & $\mathrm{X}$ & & & \\
\hline $\mathbf{5 3 3 3}$ & & & & & $\mathrm{X}$ & & & \\
\hline $\mathbf{5 3 4 1}$ & & $\mathrm{XA}$ & & & & & & \\
\hline $\mathbf{5 3 4 7 - 4 9}$ & & $\mathrm{XA}$ & & & $\mathrm{X}$ & & & \\
\hline $\mathbf{5 3 5 1 - 5 3}$ & & $\mathrm{XC}$ & & $\mathrm{X}$ & & & & \\
\hline $\mathbf{5 3 5 6 - 5 7}$ & $\mathrm{X}$ & & & & $\mathrm{X}$ & & & \\
\hline $\mathbf{5 3 5 8 - 5 9}$ & $\mathrm{X}$ & & & $\mathrm{X}$ & & & & \\
\hline $\mathbf{5 3 6 0}$ & & & & $\mathrm{X}$ & $\mathrm{X}$ & & & \\
\hline $\mathbf{5 3 6 1}$ & & & & & $\mathrm{X}$ & & & \\
\hline $\mathbf{5 3 6 9}$ & & $\mathrm{XC}$ & & & $\mathrm{X}$ & & & \\
\hline $\mathbf{5 3 7 0 - 7 2}$ & & $\mathrm{XB}$ & & & & & & $\mathrm{X}$ \\
\hline $\mathbf{5 3 7 3 - 7 5}$ & $\mathrm{X}$ & & & & $\mathrm{X}$ & & & \\
\hline Cantidad & 3 & 5 & & 3 & 11 & & & 1 \\
\hline Porcentaje & 13,0 & 21,7 & & 13,0 & 47,8 & & & 4,3 \\
\hline
\end{tabular}

Tabla 4. Asociaciones contextuales del sector Sur.

\begin{tabular}{|c|c|c|c|c|c|c|c|c|}
\hline Tumba & 1 & 2 & 3 & 4 & 5 & 6 & 7 & 0 \\
\hline 3942 & $\mathrm{X}$ & & & & & & & \\
\hline 3953-62 & & XA & $\mathrm{X}$ & & $X$ & & & \\
\hline 3963-69 & $X$ & & & $X$ & & & & \\
\hline $3970-71$ & $X$ & & & $X$ & $\mathrm{X}$ & & & \\
\hline 3974 & & $\mathrm{XC}$ & & & & & & \\
\hline 3980 & & & & & & & $\mathrm{X}$ & \\
\hline 3981 & & & & $X$ & & & & \\
\hline $3982-84$ & & & & & & & & $\mathrm{X}$ \\
\hline 3987 & & & $X$ & $X$ & & & & \\
\hline $3990-91$ & $X$ & & & & & & & $\mathrm{X}$ \\
\hline 3994 & & & & $\mathrm{X}$ & & & & $\mathrm{X}$ \\
\hline 3996-97 & & & & $X$ & & & & $\mathrm{X}$ \\
\hline 4006-07 & & & & & & $\mathrm{X}$ & & \\
\hline 4010 & $X$ & & & & & & & \\
\hline 4011 & $\mathrm{X}$ & & & $\mathrm{X}$ & & & & \\
\hline 4012-13 & $\mathrm{X}$ & & & $X$ & $\mathrm{X}$ & & & \\
\hline 4026 & & & & $\mathrm{X}$ & & & & $X$ \\
\hline 4031-33 & & & & & & $\mathrm{X}$ & & \\
\hline 4035-39 & & & & $X$ & & & & \\
\hline 4041 & $\mathrm{X}$ & & & & & & & $\mathrm{X}$ \\
\hline 4044-45 & $X$ & & & $X$ & $X$ & & & \\
\hline 4046 & & & & & & & $\mathrm{X}$ & \\
\hline 4059 & & & & & & & $\mathrm{X}$ & \\
\hline 4060 & & & & & & & & $\mathrm{X}$ \\
\hline 4061 & & AC & & & $X$ & & & \\
\hline 4065 & $\mathrm{X}$ & & & & $\mathrm{X}$ & & & \\
\hline 4066-68 & & $\mathrm{XC}$ & & & & & & \\
\hline 4099 & & $\mathrm{XC}$ & & & & & & \\
\hline 4103 & & $\mathrm{XC}$ & & $\mathrm{X}$ & $\mathrm{X}$ & & & \\
\hline 4104 & $X$ & & & $X$ & $\mathrm{X}$ & & & \\
\hline 4105 & $\mathrm{X}$ & & & & $X$ & & & \\
\hline 4106 & $X$ & & & & & & & \\
\hline 4109 & & & $\mathrm{X}$ & & & & & \\
\hline 4111 & $\mathrm{X}$ & & & $\mathrm{X}$ & & & & \\
\hline 4112-13 & $X$ & & & & & & & \\
\hline 4117 & & & & & & & & $\mathrm{X}$ \\
\hline 4142 & $\mathrm{X}$ & & & & & & & \\
\hline 4156 & & & $\mathrm{X}$ & & & & & \\
\hline 4166 & & & & & & $\mathrm{X}$ & & \\
\hline $4182-84$ & & XA & & & & & & \\
\hline 4194-99 & & $\mathrm{XA}$ & & & & & & \\
\hline $4200-02$ & $\mathrm{X}$ & & & $\mathrm{X}$ & & & & \\
\hline 5376 & $\mathrm{X}$ & & & & & & & \\
\hline $5377-80$ & $\mathrm{X}$ & & $\mathrm{X}$ & $\mathrm{X}$ & $\mathrm{X}$ & & & \\
\hline 5381 & $\mathrm{X}$ & & & & & & & \\
\hline 5383 & & & & & $\mathrm{X}$ & & & $\mathrm{X}$ \\
\hline Cantidad & 20 & 8 & 5 & 16 & 12 & 3 & 3 & 9 \\
\hline Porcentaje & 26,3 & 10,5 & 6,5 & 21,0 & 15,7 & 3,9 & 3,9 & 11,8 \\
\hline
\end{tabular}


Tabla 5. Asociaciones contextuales del sector Norte

\begin{tabular}{|l|l|l|l|l|l|l|l|l|}
\hline Tumba & 1 & 2 & 3 & 4 & 5 & 6 & 7 & 0 \\
\hline $\mathbf{4 0 7 4}$ & & & & & & $\mathrm{X}$ & & \\
\hline $\mathbf{4 1 2 4}$ & & & & & & & & $\mathrm{X}$ \\
\hline $\mathbf{4 1 2 7 - 2 8}$ & & & & & & $\mathrm{X}$ & & \\
\hline $\mathbf{4 1 3 0 - 3 1}$ & & & & & & $\mathrm{X}$ & & \\
\hline $\mathbf{4 1 3 7 - 3 9}$ & & $\mathrm{XC}$ & & $\mathrm{X}$ & & & & \\
\hline $\mathbf{4 1 4 4}$ & & & & & & $\mathrm{X}$ & & \\
\hline $\mathbf{4 1 5 7}$ & & & & & $\mathrm{X}$ & $\mathrm{X}$ & & \\
\hline $\mathbf{4 1 5 9 - 6 0}$ & & & & $\mathrm{X}$ & & & & $\mathrm{X}$ \\
\hline $\mathbf{4 1 6 7}$ & & & & & & $\mathrm{X}$ & & $\mathrm{X}$ \\
\hline $\mathbf{4 1 7 4 - 7 9}$ & & & & & & $\mathrm{X}$ & & \\
\hline Cantidad & & 1 & & 2 & 1 & 7 & & 3 \\
\hline Porcentaje & & 7,1 & & 14,2 & 7,1 & 50,0 & & 21,4 \\
\hline
\end{tabular}

asocian a los tipos 1, 2, 4 y 5; en el sector Sur, 46 tumbas asociadas a los tipos 1, 2, 3, 4, 5, 6 y 7; y, en el sector Norte, 10 tumbas con los tipos 2, 4, 5, y 6 . En los tres sectores hay presencia de alfarería atípica (Tipo 0).

\section{Parafernalia psicotrópica}

Para Coyo Oriente Le Paige registra 68 tabletas para alucinógenos, las cuales se distribuyen en los sectores de acuerdo a los siguientes IR, considerando número de tabletas en relación a número de tumbas: Sur-Sur: $(9 / 40)=22,5 \%$; Sur: $(44 / 104)=42,3 \%$; Norte: $(15 / 65)=23,0 \%$.

Once de las tabletas de este sitio se adscriben a la iconografía Tiwanaku. Todas ellas presentan un formato trapezoidal de amplio panel, el que ocupa la mitad del artefacto y sobre el cual se ha diseñado la representación bidimensional en técnicas de grabado, sobrerrelieve o combinación de ambas. Utilizando la clasificación desarrollada por Llagostera (2006a), estos ejemplares se pueden segregar en los siguientes taxones iconográficos: 1. Antropomorfos en panel plano mostrando un personaje de complejo atuendo con un relevante tocado cefálico, el que aparece en dos variantes: a) dos ejemplares con brazos desplegados portando cetros, uno de ellos en plano-frontal compacto (4093-95) y el otro en plano-frontal distendido (4010); b) dos ejemplares con manos sobre el pecho en plano-frontal compacto

(5351-54 y 3944). 2. Cefalomorfo sin aditamentos en plano-frontal cubicular (3935); 3. Falconimorfo en plano-lateral (5381) (Figura 4 a-f); 4. Camelidomorfos en plano-lateral (4049 y 5298-302); 5. Antropo-felino-ornitomorfos en plano lateral (4141 y 4008); y 6. Representación indeterminada, consistente en tres diseños cintiformes que terminan en cabezas de felinos (4111) (Figura 5 a-e). Estas tabletas Tiwanaku se distribuyen de la siguiente forma: dos en la zona Sur-Sur, ocho en la zona Sur y una en la zona Norte.

Un grupo de tabletas se aparta iconográficamente de los patrones Tiwanaku; portan decoraciones volumétricas y no volumétricas, y todas son diferentes entre sí. Tal vez, la única coincidencia entre ellas es la tendencia de su formato hacia una rectangularidad de su contorno con lados rectos en paralelo.

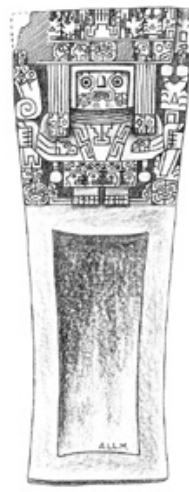

a

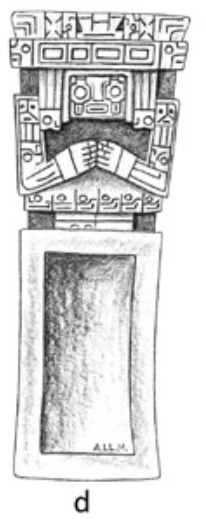

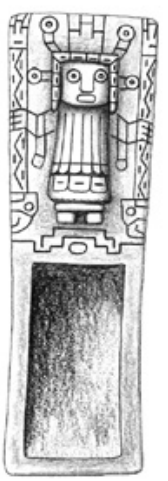

b

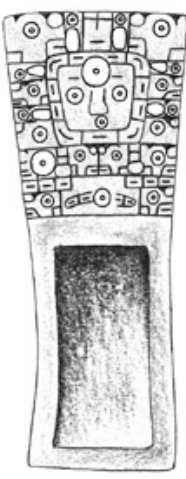

e

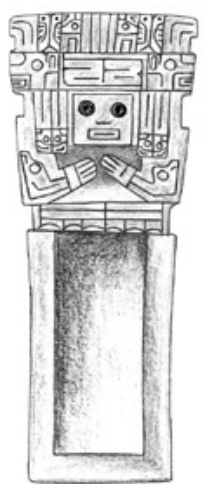

C

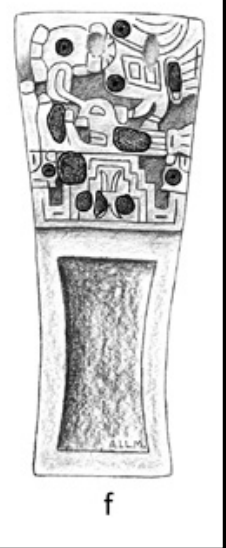

Figura 4. Tabletas Tiwanaku: (a) 4093-95, (b) 4010, (c) 5351-54, (d) 3944, (e) 3935, (f) 5381. 


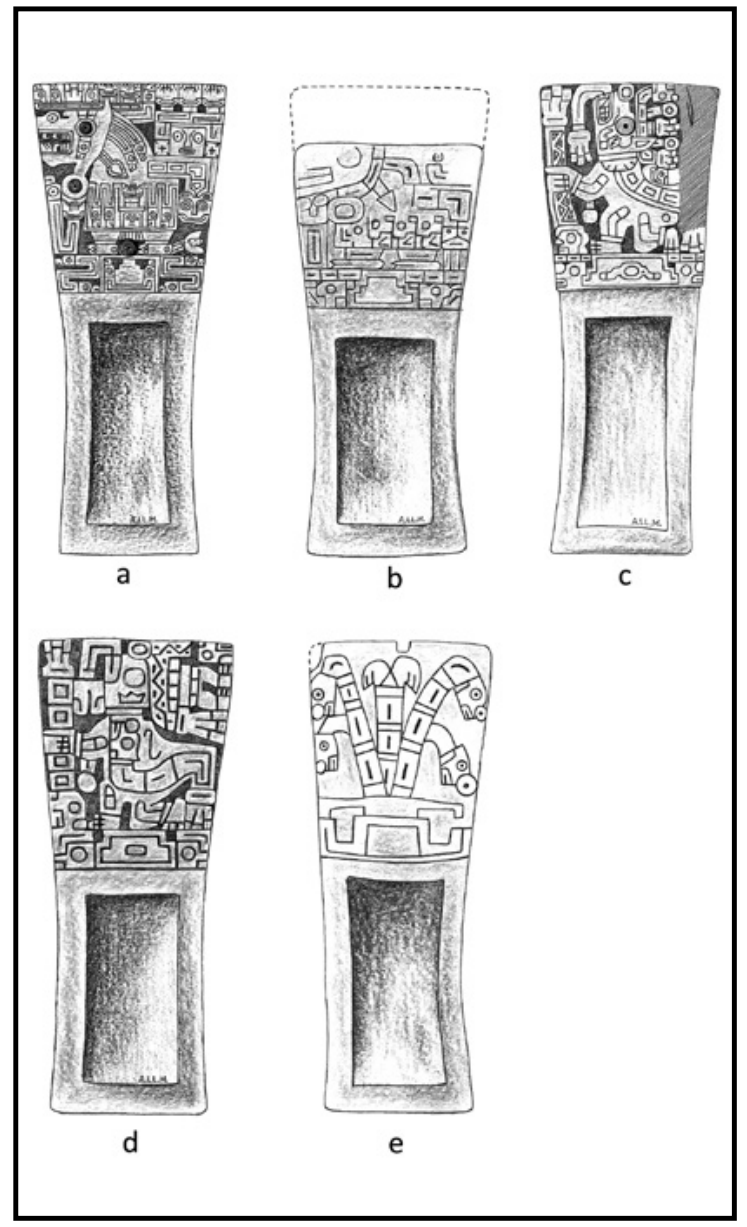

Figura 5. Tabletas Tiwanaku: (a) 4049, (b) 5298-302, (c) 4141, (d) 4008, (e) 4111.

Predominan en ellas representaciones antropomorfas y zoomorfas: 1. Antropomorfas: un personaje volumétrico de contextura maciza en posición acuclillado (4120); personajes duplos esculpidos en relieve sobre el panel, portando cada uno de ellos una falcónida sobre su cabeza, aves que se proyectan tridimensionalmente por sobre el borde superior del panel (4027-30); dos personajes en formatos rectangulares (4040); dos personajes portando cada uno un cetro (3975); una cabeza humana que se yergue sobre el borde superior de la tableta (5373-75); dos cabezas humanas en altorrelieve sobre el panel con relevantes tocados (4109); una mano empuñada (3974). 2. Zoomorfas: felino ejecutado en una compleja estilización (4142); felino moteado en una estilización sencilla (4040); animal indefinido de lomo arqueado al que le falta la cabeza (4041); cóndor volumétrico mirando de lado (4105 y 4135 36); cóndor volumétrico en rígida posición vertical (4135-36); dos ofidios que entrecruzan sus cuerpos y poseen cada uno una cabeza en sus dos extremos (5383). 3. No figurativos: panel en forma de un reducido rectángulo, con una serie de escarificaciones en su superficie, el que se une a la caja por una especie de cuello; posiblemente sea un remedo de cabeza humana (4011); panel plano recortado de manera de proyectar un perfil radiado, además presenta dos incrustaciones en su línea sagital (4129). La mayor concentración de esta categoría de tabletas se produce en el sector Sur (10 ejemplares), en tanto que en los sectores Sur-Sur y Norte se hace presente en mínima cantidad ( 1 y 3) (Figura 6).

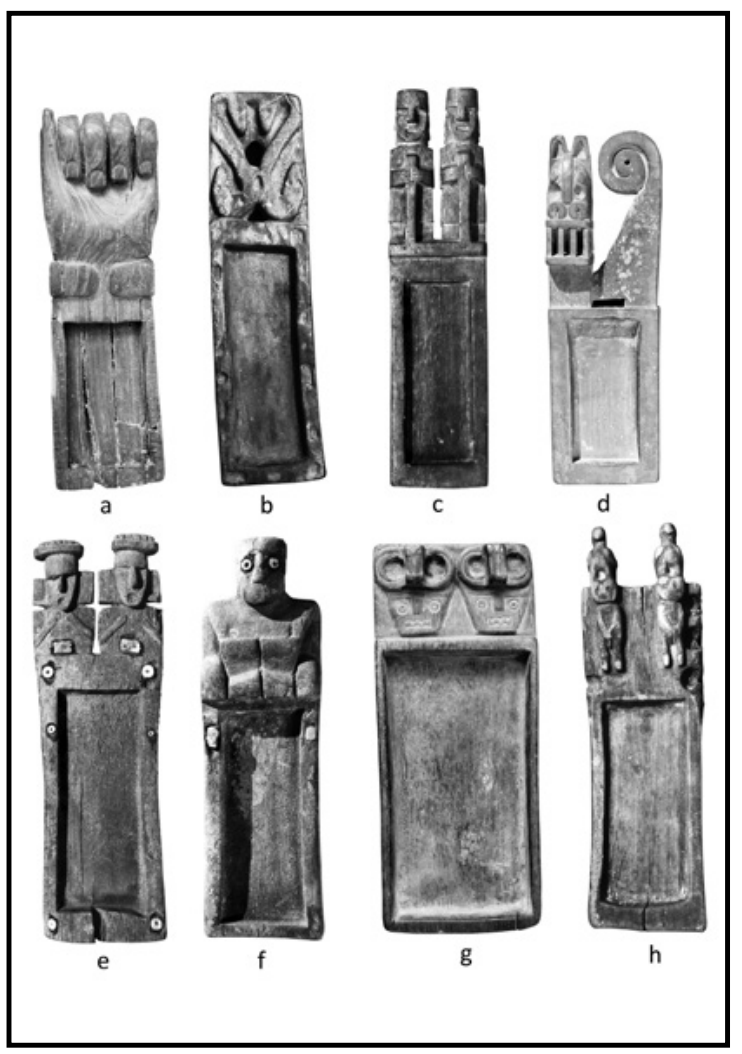

Figura 6. Tabletas No Tiwanaku: (a) 3974, (b) 5383, (c) 3975, (d) 4142, (e) 4040, (f) 4120, (g) 4109, (h) 4027-30.

Un grupo mayor de tabletas carece de iconografía o exhibe una decoración muy simple, disponiendo de un amplio panel, el que ocupa la mitad o poco menos del largo total del artefacto. De acuerdo al 


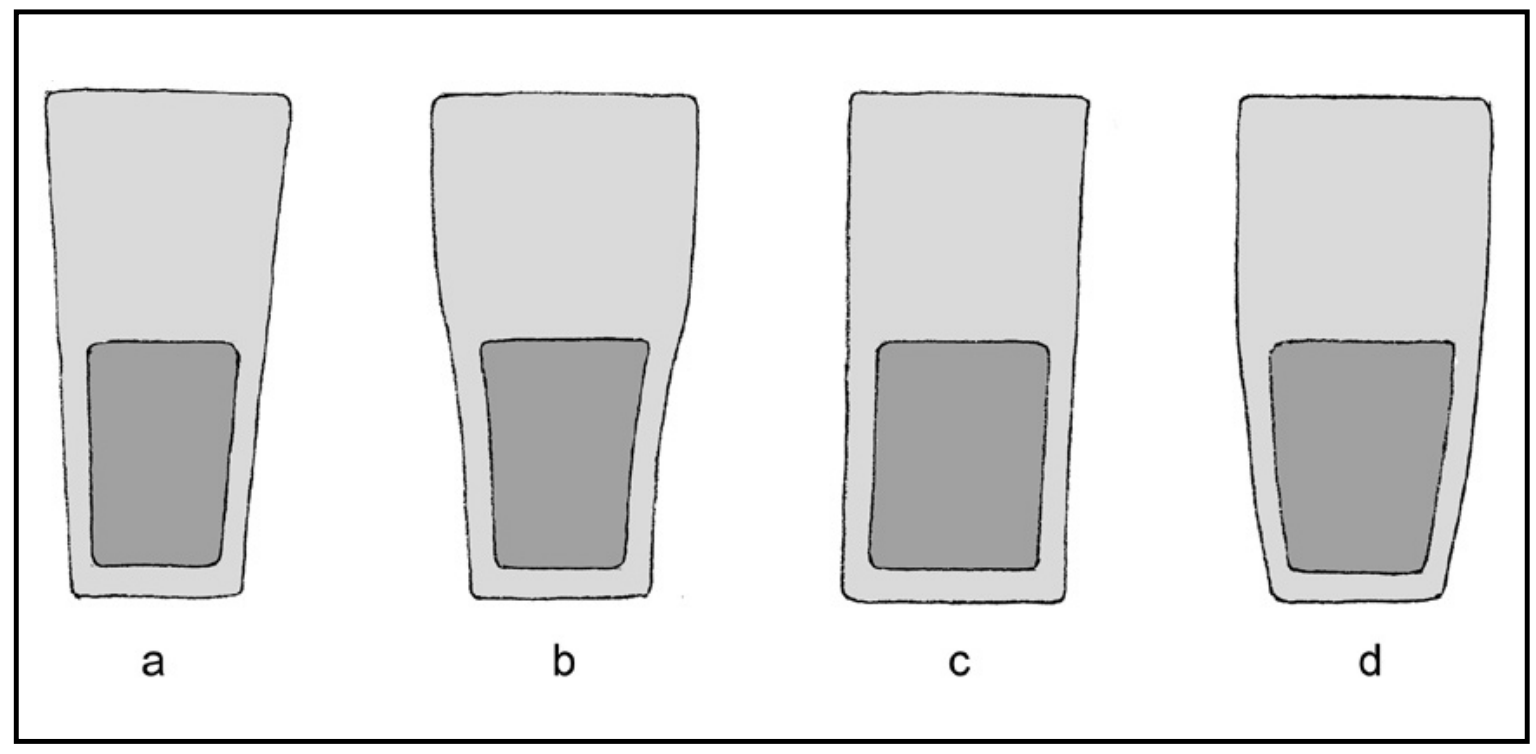

Figura 7. Formatos de tabletas simples: (a) Tabletas de lados divergentes (Trapezoidales),

(b) Tabletas de lados cóncavo-convexos, (c) Tabletas de lados rectos paralelos, (d) Tabletas de lados convexos.

perfil lateral del contorno, estos ejemplares pueden clasificarse en: 1. Tabletas de lados divergentes (trapezoidales) (3912, 3942, 3945, 3970-71, 4048, 404950, 4084-86, 4092, 4097, 4147, 5292, 5327-28, 5333, 5369, 5376, 5382) (Figura 7a). 2. Tabletas de lados cóncavo-convexos (3942, 3945, 4048, 408486, 4049-50, 4110) (Figura 7b). 3. Tabletas de lados rectos paralelos (4019-21, 5376) (Figura 7c). 4. Tabletas de lados convexos (4024-25, 4147, 4190-91) (Figura 7d). Algunos ejemplares presentan como única decoración incrustaciones de piedra en el panel, situación que se manifiesta especialmente en las tabletas del sector Norte. Dos tabletas presentan un grabado ornamental simple (4022-23 y 5369) y otras dos fueron confeccionadas en piedra (3942 y 5350). El grupo 1 es el más representativo con 16 ejemplares, haciéndose presente en los tres sectores, con decrecimiento en su IR de sur a norte $(10 \% ; 7,6 \% ; 4,6 \%)$. El grupo 2 le sigue con seis ejemplares, grupo ausente en el sector Sur-Sur y aumentando su presencia hacia el norte $(2,8 \%$; $4,6 \%)$. Los grupos 3 y 4 , con escasos ejemplares, están presentes en los sectores Sur y Norte pero ausentes en el sector Sur-Sur. En consecuencia, el grupo 1 ya viene desde el sector Sur-Sur y va perdiendo vigencia hacia el norte; en cambio, los grupos 2,3 y 4 aparecen recién en el sector Sur y continúan hacia el sector Norte.
Hay una cantidad menor de tabletas que exhibe un reducido panel plano o carece de este aditamento, posiblemente debido a pérdida de este por quebradura y posterior retoque del borde fracturado (4119 y 4044-45).

Los tubos para inhalar alucinógenos han sido confeccionados en madera, hueso o caña. Entre los de madera se encuentran los de filiación Tiwanaku, caracterizados por exhibir en su extremo distal la representación esculpida de una cabeza de camélido. Algunos de estos ejemplares portan además, en la parte media del tubo, una figura asimilable a los monolitos tiwanakotas o, en su lugar, dos cabezas felínicas contrapuestas, estampadas en técnica de grabado. Estos ejemplares han sido confeccionados en una sola pieza, habiéndose labrado en el extremo proximal una emboquilladura cónica. Otros ejemplares de madera, al igual que los de caña, no presentan decoración. Algunos ejemplares de hueso presentan decoración pirograbada muy simple, aunque la mayoría carece de ella. En los tubos No Tiwanaku, ya sean de madera, hueso o caña, la emboquilladura es agregada y confeccionada en madera o en piedra. 


\section{Textiles}

Oakland (1992) distingue dos estilos textiles en el vestuario de los individuos inhumados en el cementerio de Coyo Oriente. Grupo A: túnicas rectangulares beige y con listas laterales en cinco variaciones; desde una simple lista hasta un bloque de listas, rojas, blancas y café situadas entre anchas franjas verde/azul. Grupo B: túnicas con listados laterales en rojo, azul, verde, café, amarillo y café rojizo, como también con listado solo a un costado; entre estas se encuentran ejemplares decorados, túnicas teñidas por amarras y túnicas en tapicería con íconos Tiwanaku. Mientras los bordados del grupo A son fluidos, curvos y orgánicos, los del grupo B son rígidos, en ángulos rectos y geométricos.

De las 57 tumbas analizadas por Oakland, 21 las considera del grupo A, de las cuales tres se ubican en el sector Sur-Sur, nueve en el sector Sur y nueve en el sector Norte; las otras 36 las asigna al grupo B y se distribuyen tres en el sector Sur-Sur, 29 en el sector Sur y cuatro en el sector Norte. En suma, los dos grupos están presentes en los tres sectores.

Por su parte, Agüero (2003) registra un total de 281 piezas textiles en el cementerio de Coyo Oriente, de las cuales 270 corresponderían al estilo local, 10 a Tiwanaku y una de estilo relacionado con Cochabamba (Bolivia).

\section{Tipas o cestos bordados}

En Coyo Oriente se registra una variedad de cestería similar a la que en el NOA es denominada "tipa", descrita como "con adornos de lana en colores sepia, rojo y ocre, formando un felino o llama" (Ibarra, 1971) (Figura 8a). Dado que ese tipo de cestería se asocia con la Cultura Aguada, Llagostera (1995) las considera como parte del componente Aguada en San Pedro de Atacama. Para Coyo Oriente se registran 12 tumbas que contienen tipas, de las cuales tres se ubican en el sector Sur-Sur $(5277,344$ y 5347-49), siete en el sector Sur (3927, 4009, 4010, $4040,4042-43$, 4194-99 y 5377-80) y dos en el sector Norte (4058 y 4110). En siete casos estos artefactos aparecen asociados con mujeres. De las 12 tumbas, solo tres de ellas se asocian con alfarería: las tumbas 3927 y 4194-99 portan una vasija cada una, en cambio, la tumba 5377-80 tiene 20 piezas, cantidad que resulta elevada para el promedio general del cementerio. Sin embargo, por tratarse de una tumba múltiple, esta cantidad no puede asociarse exclusivamente con el portador de la tipa. Las tumbas 4010 y 4040, que corresponden a varones, incluyen un hacha de metal la primera y un hacha simbólica la segunda; la 5277 se asocia con objetos metálicos (cinta, placa y pulsera de plata).

La distribución de este tipo de cestería se presenta de la siguiente forma: Sur-Sur: 2/40 (5,0\%), Sur: 7/104 (6,7\%) y Norte: $2 / 65$ (3,0\%).

\section{Objetos de metal}

Once tumbas de Coyo Oriente registran objetos de metal, los que se pueden clasificar en las siguientes categorías: puntas de cinceles (3944, 4048 y 4142), colgantes de cuatro puntas "campanitas" (4011 y 4141), anillos (4119), adornos (5314-15) y pinzas (5361-66). En relación a su IR por sectores, la distribución es la siguiente: Sur-Sur: 3/16 (18,7\%), Sur: $7 / 46(15,2 \%)$ y Norte: $1 / 10(10,0 \%)$.

\section{Hachas y mazos}

En relación a los mazos y hachas, vemos que en el sitio se registran: un mazo de piedra (3935), tres hachas de metal (4010, 4109 y 5327-28), cinco hachas de piedra (3973, 4048, 4118, 4142 y 4163-65), a las que se suman nueve hachas simbólicas de hueso o de piedra (3933, 4040, 4049-50, 4079-82, 4093-95, $4111,4141,5381$ y 5383). Mientras que el mazo y las hachas de metal se ubican en el sector Sur, las hachas de piedra y simbólicas se las encuentra en los sectores Sur y Norte, no hallándose ninguno de estos artefactos en el sector Sur-Sur. Los ejemplares que se han nominado como "hachas simbólicas" son aquellos en los que la hoja ha sido reemplazada por un tosco remedo de piedra o hueso; en este último caso puede ser un omóplato de animal.

\section{Miscelánea}

Conchas de Strophocheilus: las conchas del caracol transandino Strophocheilus se distribuyen por sectores de la siguiente forma: Sur-Sur: $(3 / 40)=7,5 \%$, Sur: $(26 / 104)=25,0 \%$ y Norte: $(5 / 65)=7,6 \%$. 
Martillos: son artefactos compuestos por una cabeza de piedra de forma irregular, la que se aproxima al cilindro o al cono y un mango que consiste en una rama que rodea la cabeza siguiendo una escotadura que circunda la pieza para luego unir las extremidades por medio de amarres para constituir el mango. Existen siete piezas en el sector Sur-Sur (7/40 $=17,5 \%), 21$ en el sector Sur $(21 / 104=20,1 \%)$ y tres en el sector Norte $(3 / 65=4,6 \%)$. Todas ellas se asocian con varones.

Muñeca de madera: una figura femenina tridimensional tallada en madera hace parte del contexto funerario de la tumba 4200-02, la cual ha sido identificada como perteneciente a la Cultura Aguada (Berenguer, 1984; Llagostera, 1995) (Figura 8b).

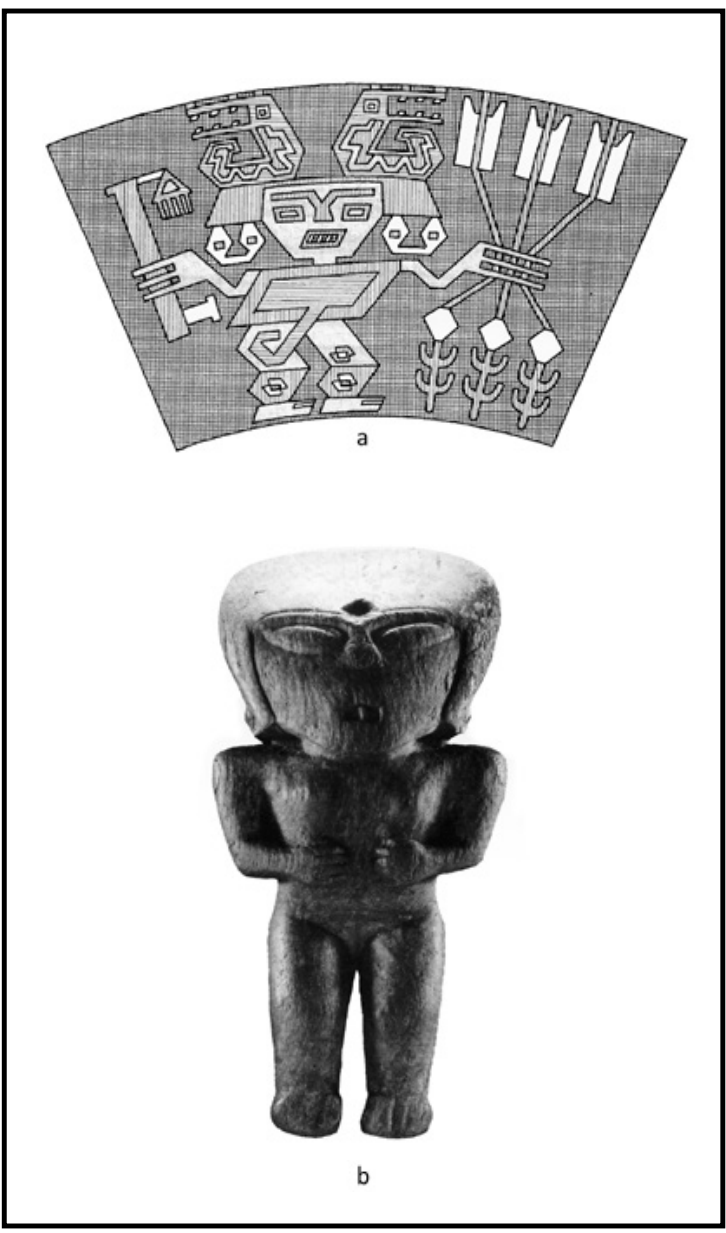

Figura 8. Componentes de la Cultura Aguada: (a) panel de cestería "tipa” con clásica iconografía Aguada (4010),

(b) muñeca de madera (4200-02).

\section{Bioantropología}

Considerando la deformación artificial del cráneo como uno de los factores que al tiempo de caracterizar una comunidad puede también indicar cambios diferenciales a nivel diacrónico como también sincrónico, hemos enfatizado este aspecto en la contextualización bioantropológica de Coyo Oriente. Para el análisis de deformación y sexo se logró disponer de 219 individuos adultos.

A nivel general del sitio, el $48,4 \%$ de los individuos presenta el tipo tabular erecto (TE), correspondiendo a femeninos $56,6 \%$ y masculinos el $43,3 \%$. El $42,9 \%$ de la población no presenta el cráneo deformado (ND), y hay proporciones prácticamente iguales entre hombres y mujeres. El tipo deformatorio circular erecto (CE) alcanza $5,0 \%$, y es mucho más popular entre las mujeres $(72,7 \%)$ que entre los hombres $(27,2 \%)$. El circular oblicuo $(\mathrm{CO})$ es aún menos frecuente, con solo $2,7 \%$ de representación, mayormente usado por las mujeres $(83,3 \%)$, y solo el $16,6 \%$ de los hombres (Tabla 6).

En los tres sectores predominan las formas tabulares y normales y son escasos los ejemplares circulares. Desde el sector más temprano al más tardío se observa que tanto los tipos tabulares como los no deformados sufren una variación mínima, disminuyendo los primeros $(59,8 \% ; 49,0 \%$ y $41,9 \%)$ y aumentando los segundos (37,7\%; 43,6\% y $45,0 \%)$; en tanto los circulares se incrementan en la dirección señalada $(2,2 \% ; 7,0 \%$ y $12,9 \%)$.

En el rubro de patologías, resulta interesante considerar la existencia de cuatro cráneos con extensas lesiones destructivas en sus rostros, los que fueron diagnosticados como afectados por la enfermedad transandina, tropical y subtropical, conocida como leishmaniasis (Costa et al., 2009; Costa y Llagostera, 2014). Se trata de individuos femeninos de entre 30 y 40 ańos de edad; uno de ellos presenta deformación TE, otro tiene la variedad CO y los dos restantes no están deformados. Los cuatro individuos fueron exhumados en la zona Sur (3938, 3984,4156 y 5377-80). Los contextos de las tumbas de estos individuos no difieren mayormente del común de los enterratorios del cementerio de Coyo 
Tabla 6. Distribución de los tipos de deformación craneana por sectores, segregando entre individuos masculinos y femeninos.

\begin{tabular}{|c|c|c|c|c|}
\hline Deformación y sexo & Sur-Sur & Sur & Norte & Subtotales \\
\hline $\begin{array}{l}\text { No deformados }(\mathrm{N}) \\
\text { Femeninos } \\
\text { Masculinos }\end{array}$ & $\begin{array}{r}17(37,7 \%) \\
8(17,7 \%) \\
9(20,0 \%)\end{array}$ & $\begin{array}{l}49(43,6 \%) \\
26(23,2 \%) \\
23(20,4 \%)\end{array}$ & $\begin{array}{r}28(45,0 \%) \\
14(22,5 \%) \\
14(22,5 \%)\end{array}$ & $\begin{array}{l}94(42,9 \%) \\
48(51,0 \%) \\
46(48,9 \%)\end{array}$ \\
\hline $\begin{array}{l}\text { Tabular Erecto (TE) } \\
\text { Femeninos } \\
\text { Masculinos }\end{array}$ & $\begin{array}{l}26(57,6 \%) \\
13(28,8 \%) \\
13(28,8 \%) \\
\end{array}$ & $\begin{array}{l}55(49,0 \%) \\
31(27,6 \%) \\
24(21,4 \%) \\
\end{array}$ & $\begin{array}{r}25(40,3 \%) \\
16(25,8 \%) \\
9(14,5 \%)\end{array}$ & $\begin{array}{r}106(48,4 \%) \\
60(56,6 \%) \\
46(43,3 \%) \\
\end{array}$ \\
\hline $\begin{array}{l}\text { Tabular Oblicuo (TO) } \\
\text { Femeninos } \\
\text { Masculinos }\end{array}$ & $\begin{array}{l}1(2,2 \%) \\
1(2,2 \%)\end{array}$ & & $\begin{array}{l}1(1,6 \%) \\
1(1,6 \%)\end{array}$ & $\begin{array}{c}2(0,9 \%) \\
2(100 \%)\end{array}$ \\
\hline $\begin{array}{l}\text { Circular Erecto (CE) } \\
\text { Femeninos } \\
\text { Masculinos }\end{array}$ & & $\begin{array}{l}5(4,4 \%) \\
4(3,5 \%) \\
1(0,9 \%)\end{array}$ & $\begin{array}{l}6(\mathbf{9 , 7} \%) \\
4(6,5 \%) \\
2(3,2 \%)\end{array}$ & $\begin{array}{l}11(5,0 \%) \\
8(72.7 \%) \\
3(27,2 \%)\end{array}$ \\
\hline $\begin{array}{l}\text { Circular Oblicuo (CO) } \\
\text { Femeninos } \\
\text { Masculinos }\end{array}$ & $\begin{array}{l}1(2,2 \%) \\
1(2,2 \%)\end{array}$ & $\begin{array}{l}3(2,6 \%) \\
3(2,6 \%)\end{array}$ & $\begin{array}{l}2(3,2 \%) \\
2(3,2 \%)\end{array}$ & $\begin{array}{r}6(2,7 \%) \\
5(83,3 \%) \\
1(16,6 \%)\end{array}$ \\
\hline Subtotales & $45(100 \%)$ & $112(100 \%)$ & $62(100 \%)$ & 219 \\
\hline
\end{tabular}

Tabla 7. Mortalidad infantil de acuerdo al porcentaje de infantes en relación al número de individuos adultos del sector correspondiente.

\begin{tabular}{|c|c|c|c|}
\hline Sectores & Sur-Sur & Sur & Norte \\
\hline Mortalidad Infantil & $22,6 \%(19 / 84)$ & $18,5 \%(34 / 183)$ & $17,0 \%(20 / 117)$ \\
\hline
\end{tabular}

Oriente, no destacando ni desmereciendo en cantidad y calidad el promedio del resto de los ajuares del cementerio.

Le Paige, en su registro de tumbas de Coyo Oriente califica a los individuos en rangos de "guagua", "niño" y "adulto", lo que permite hacer una estimación de la mortalidad infantil (Tabla 7), la que se presenta bastante moderada y, aunque va disminuyendo de sur a norte, no refleja diferencias mayormente significativas entre uno y otro sector, lo cual denota que esta población no estuvo sujeta a ningún estrés ambiental o social, por el contrario, la disminución de la mortalidad infantil, aunque leve, arguye a favor de una mayor estabilidad y posesionamiento de la población en la localidad.

\section{Discusión}

Como hemos visto, Coyo Oriente fue tomado como sitio-tipo para nominar la fase $\mathrm{V}$ de la periodificación elaborada por Tarragó para el Período
Agroalfarero de San Pedro de Atacama (Berenguer et al., 1986). Esta fase fue definida originalmente por Tarragó, por la presencia de cerámicas San Pedro Negro Pulido en disminución, San Pedro Negro y Rojo Grabado, Gris Pulido Grueso y Tiwanaku Transformado (Tarragó, 1989). Más tarde, la misma autora detalla con mayor precisión el contexto alfarero señalando que en la fase Coyo es característica la agrupación 11, ajuares con Gris Pulido Grueso solo o combinados con vasos grabados tipo Tchecar, cuencos mitad negro mitad rojo y/o vasijas alisadas; también puede combinarse con vasijas de las clases 9 y 10 de los tazones negros o rojos grabados. Agrega que esta clase de asociación viene a representar al grupo "casi pulido" de Le Paige, pero lo trasciende pues incluye una mayor variación formal y varias combinaciones. Estas consideraciones no fueron obtenidas directamente de Coyo Oriente sino de otros sitios, tales como Séquitor Oriental, Solor 3 y 5 , Tchecar, Quitor 2, 5, 6 y 8. Por su parte, Berenguer et al. (1986), luego de aplicar su test por termoluminiscencia, en el que tampoco se incluyó muestras de 
Coyo Oriente, asignaron como rango cronológico estimativo para la fase, entre 700 y 1000 DC.

De nuestro análisis de Coyo Oriente vemos que el IR de los tipos alfareros por sectores se manifiesta de la siguiente forma. El sector Sur-Sur está conformado preferentemente por los tipos $5(47,8 \%)$ y 2 $(21,7 \%)$ y minoritariamente por los tipos $1(13,0 \%)$ y $4(13,0 \%)$; el sector Sur preferentemente por los tipos $1(26,3 \%), 4(21,0 \%), 5(15,7 \%)$ y $2(10,5 \%)$ y en menor proporción los tipos $3(6,5 \%), 6(3,9 \%)$ y $7(3,9 \%)$; en el sector Norte la representatividad preferente involucra a los tipos $6(50,0 \%)$ y 4 $(14,2 \%)$ y la menor a los tipos $4(7,1 \%)$ y $5(7,1 \%)$ (Tabla 8).

Tabla 8. Índice de Representatividad (IR) de los tipos alfareros en cada uno de los sectores de Coyo Oriente.

\begin{tabular}{|c|c|c|}
\hline Sector sur-sur & Sector sur & Sector norte \\
\hline Tipo 5: $47.8 \%$ & Tipo 1: $26.3 \%$ & Tipo 6: $50.0 \%$ \\
\hline Tipo 2: $21.7 \%$ & Tipo 4: $21.0 \%$ & Tipo 0: $21.4 \%$ \\
\hline Tipo 1: $13.0 \%$ & Tipo 5: $15.7 \%$ & Tipo 4: $14.2 \%$ \\
\hline Tipo 4: $13.0 \%$ & Tipo 0: $11.8 \%$ & Tipo 2: 7.1\% \\
\hline Tipo 0: $4.3 \%$ & Tipo 2: $10.5 \%$ & Tipo 5: 7.1\% \\
\hline & Tipo 3: $6.5 \%$ & \\
\hline & Tipo 6: 3.9\% & \\
\hline & Tipo 7: 3.9\% & \\
\hline
\end{tabular}

La secuencia de los tipos alfareros a través de los tres sectores es variable. Algunos de los tipos son exclusivos de determinados sectores, pero otros se hacen presentes en más de uno de ellos, manifestando cierta transversalidad pero también modulaciones, mostrando un mayor predominio en alguno de ellos (Tabla 8). Los tipos 2, 4 y 5 se hacen presentes en los tres sectores: los tipos 2 y 5 están fuertemente representados en el sector Sur-Sur, disminuyendo notoriamente en los otros sectores; el tipo 4 manifiesta una moderada presencia en el sector Sur-Sur, incrementándose fuertemente en el Sur, y decayendo nuevamente en el Norte. El tipo 1 se hace presente solamente en los sectores Sur-Sur y Sur con un fuerte incremento en el Sur. El tipo 6 se encuentra en los sectores Sur y Norte con fuerte presencia en este último. Los tipos 3 y 7 son exclusivos del sector Sur.
En síntesis, en el sector Sur se observa una continuidad de los tipos del sector Sur-Sur (1, 2, 4 y 5), privilegiando con mayor énfasis los tipos 1 y 4, a los que se agregan tres tipos nuevos (3, 6 y 7). Del bagaje tipológico del sector Sur se transfieren al sector Norte los tipos 2, 4, 5 y 6, tomando el último de estos una fuerte representatividad. Sin duda, el sector con mayor desarrollo contextual es el sector Sur con un despliegue de siete tipos, lo que junto con presentar el mayor número de tumbas, refleja lo medular del asentamiento y el posicionamiento de la comunidad en el distrito de Coyo. Al mismo tiempo, entre el sector Sur-Sur y Sur se manifiesta un proceso continuo que va de menos a más, develando la evolución de una población colonizadora emergente hacia una población que logra el clímax de consolidación; en cambio, entre el sector Sur y el sector Norte se manifiesta una evidente merma del contexto alfarero con una notoria simplificación de sus componentes (50\% representado por platos), lo que refleja un evidente cambio, no solo cuantitativo sino cualitativo, reforzado por la separación física (espacio sin tumbas) que existe entre estos dos sectores.

El contexto alfarero del sector Norte se asimilaría a la fase VI de Tarragó (fase Yaye), la cual se caracteriza por que los recipientes cerámicos se limitan a escudillas o platos grisáceos (clases 12.0, 12.1, 12.4) o son reemplazados por calabazas. La cantidad y calidad de los ajuares fúnebres muestran una perceptible disminución y es una época en que han finalizado las situaciones de interacción con Tiwanaku. El conjunto de la fase sugiere que las tradiciones socioculturales se han encauzado por un rumbo distinto al de las épocas previas (Tarragó, 1989).

Para la fase Yaye se postulan fechas de 950-1200 DC (Tarragó, 1989). Torres-Rouff y Hubbe (2013), presentan fechas tomadas de cuatro sitios del distrito de Yaye (Yaye 1, 2, 3 y 4) registrando una serie de dataciones entre 667-881 y 1251 1260 ańos cal. DC. Por nuestra parte, para el sector Norte tenemos las fechas TL de 1085 y 1230 DC (ver Tabla 2). La mayoría de estas fechas son concordantes con las que, en general, se ha postulado para la cronología del Período Intermedio Tardío, el que para San Pedro de Atacama se identificaría con la fase Yaye. 
En consecuencia, podemos afirmar que, mientras el sector Sur-Sur y el sector Sur responden a un mismo proceso de desarrollo adscrito a la fase Coyo, entre el sector Sur y el sector Norte se ha producido una inflexión evolutiva, un cambio, que ha dado paso a una nueva fase: fase Yaye. Con esto se infiere que el sitio Coyo Oriente es un cementerio bicomponente desde el punto de vista del proceso secuencial, con representación de la fase Coyo y de la fase Yaye.

En general, las pocas tabletas de que se dispone para los inicios de la fase Coyo (sector Sur-Sur) se caracterizan por presentar formatos trapezoidales y también de lados cóncavo-convexos, con amplios paneles; además, una tableta atípica rectangular con cabeza humana volumétrica sobresaliendo del borde superior y dos ejemplares que se adscriben a la clásica iconografía Tiwanaku.

En el auge de la fase Coyo (sector Sur) se concentra la mayor cantidad de tabletas que se registra para el sitio, con una notable diversidad. Predominan los ejemplares con amplios paneles decorados o sin decorar; en el primer caso contienen representaciones iconográficas Tiwanaku. Los formatos se ajustan a los cuatro contornos descritos y los casos atípicos son varios.

En tanto, en la fase Yaye (sector Norte) las tabletas se caracterizan básicamente por mantener amplios paneles, y tanto a estos como a otros formatos se les ha aplicado incrustaciones de piedra. Entre las pocas representaciones volumétricas, es el humano en cuclillas y el cóndor los que cobran relevancia. Es interesante el caso de la tableta 4049-50 que, siendo una de las más eximias obras del arte clásico Tiwanaku, hace parte de los contextos tardíos (sector Norte); sin embargo, la forzada inserción de incrustaciones de piedra en la pieza deja en evidencia que se trata del "reciclaje" de una tableta de la fase anterior, la que fue sometida a un proceso de entronización para seguir siendo utilizada en esta nueva época y probablemente por nuevos usuarios.

El lapso cronológico de la fase Coyo de Coyo Oriente se enmarca preferentemente en el Período Medio, el que a su vez se relaciona con el evento Tiwanaku. En torno a esto último, en este sitio se registra un importante número de objetos de dicha filiación representados básicamente en los rubros del complejo psicotrópico y en los tejidos.

Del total de tabletas que hemos clasificado como de iconografía tiwanakota para este sitio, dos caen en el sector Sur-Sur, ocho en el sector Sur, y solo una en el sector Norte la que, como se dijo anteriormente, sería una tableta reciclada de la fase anterior. De los 13 tubos tiwanakotas, tres proceden del sector SurSur, nueve del sector Sur, y uno del sector Norte. De los únicos dos ejemplares de alfarería Tiwanaku, uno pertenece al sector Sur y el otro no es asignable a sector alguno (Tabla 9). En relación a los textiles Tiwanaku factibles de ser adscritos a sectores del cementerio, se reconoce tres en el sector Sur-Sur, tres en el sector Sur y uno en el sector Norte.

En general, la distribución de objetos tiwanakotas por sectores en el sitio, en relación con el número total de individuos por sector, resulta ser coherente con los índices anteriores: para el sector Sur-Sur se registra un $13,5 \%$ (11/81); para el sector Sur, un $12,2 \%(22 / 180)$ y para el sector Norte, un 3,4\% (4/116). Resulta entonces que la representación de objetos Tiwanaku en los sectores Sur-Sur y Sur (fase Coyo) es de cierta representatividad y bastante similar entre los dos sectores, en tanto que en el sector Norte (fase Yaye) hay una notable disminución, lo que pone de manifiesto que en esta última fase, la interacción con Tiwanaku se ve de alguna manera interferida, no llegando elementos de esa

Tabla 9. Proporción entre parafernalia psicotrópica con iconografía Tiwanaku y aquella que carecen de esta iconografía.

\begin{tabular}{|l|c|r|r|r|}
\cline { 2 - 5 } \multicolumn{1}{c|}{} & \multicolumn{2}{c|}{ Tabletas } & \multicolumn{2}{c|}{ Tubos } \\
\cline { 2 - 5 } & Tiwanaku & No Tiwanaku & Tiwanaku & No Tiwanaku \\
\hline Sector Sur-Sur & $2(28.5 \%)$ & $5(71.5 \%)$ & $3(27.2 \%)$ & $8(72.8 \%)$ \\
\hline Sector Sur & $8(25.0 \%)$ & $24(75.0 \%)$ & $9(22.5 \%)$ & $31(77.5 \%)$ \\
\hline Sector Norte & $1(7.6 \%)$ & $12(92.3 \%)$ & $1(6.2 \%)$ & $15(93.8 \%)$ \\
\hline
\end{tabular}


filiación al sitio; los pocos que se registran presentan evidencias de haber sido reciclados (caso de la tableta 4049-50).

Como una manera de indagar sobre el estatus de los individuos portadores de objetos Tiwanaku, realizamos una confrontación con la posesión de hachas, con la parafernalia psicotrópica, con los objetos de metal, con conchas (tanto del Pacífico como del oriente) y con la alfarería foránea. Considerando las hachas y mazos como indicadores de mando; la parafernalia psicotrópica como indicador de rango shamánico; los objetos de metal como manifiestos de ostentación de estatus (visibilizadores) y, tanto las conchas como la alfarería foránea, como indicadores del manejo de la red interactiva.

Es importante enfatizar la escasez de hachas (no simbólicas) en el sitio, especialmente las metálicas -solo ocho para una población de 384 individuos-, lo que devela que estos artefactos no estaban disponibles para cualquier poblador, sino solamente para determinadas personas, las cuales deberían haber sido investidas con un estatus de alta jerarquía en la estructura socio-política de la comunidad. Dada la escasa presencia de hachas con hojas originales es posible pensar que, a la muerte del titular, estas hojas eran transferidas al siguiente portador y reemplazadas en su tumba por piezas simbólicas. Esta costumbre no solo obedecería a la dificultad de conseguir las piezas metálicas, sino también al simbolismo implícito que ellas conllevan, lo que obligaba a que solo las piezas consagradas fueran transferibles de uno a otro mandatario. Por otra parte, se ha logrado determinar el sexo y la edad de ocho de los individuos portadores de hachas observándose que todos son varones y que los rangos de edad de fallecimiento fluctúan entre 30-34 y 45-49, con un predominio de estos últimos.

De las 11 tabletas Tiwanaku registradas para Coyo Oriente, seis de ellas forman parte de los contextos de tumbas portadoras de mazos y hachas, lo que representa una importante fracción $(6 / 18=33,3 \%)$ frente a las otras cinco que se minimizan en las 203 tumbas restantes $(5 / 203=2,4 \%)$. Por una parte, vemos que las tumbas que registran mazos y hachas se asocian todas con el complejo alucinógeno (no necesariamente Tiwanaku), lo que ya es altamente significativo en relación al resto de tumbas con parafer- nalia psicotrópica (tabletas y tubos) relacionado con el total de tumbas del sitio $(51 / 203=24,4 \%)$. Por otra parte, vemos que hay una alta representatividad de tabletas Tiwanaku en el conjunto de portadores de mazos y hachas $(33,3 \%)$, lo que a su vez vincula este grupo con la interacción transandina, ya que estas tabletas son evidentemente foráneas.

En relación a la muñeca de madera y a las "tipas" que han sido relacionadas con la Cultura Aguada del NOA, tres de estas últimas se asocian con tabletas: 4010, 4040 (con dos ejemplares) y 4110; de estas, solo la tableta de la tumba 4010 puede ser asimilable a Tiwanaku, aunque en una versión modificada del Personaje de los Cetros, escapando a las representaciones clásicas de dicho estilo. En general, la fracción portadora de "tipas" aparece menos tiwanakizada que la totalidad del sitio. En consecuencia, esta observación pone de manifiesto que la gente de Coyo Oriente habría mantenido vínculos con Tiwanaku por un lado, y con el NOA por otro, en forma independiente.

Dado que Oakland (1992) en su análisis textil sugiere que el grupo A representa al grupo étnico local, en tanto que el grupo B estaría relacionado estrechamente con Tiwanaku, nos interesa saber cómo responde este planteamiento en relación al complejo psicotrópico de dicha filiación. La proporción de tabletas Tiwanaku confrontada con el total de tabletas de cada grupo resulta ser bastante baja (Grupo A: 0/4; Grupo B: 4/24), lo mismo sucede con los tubos (Grupo A: 0/3; Grupo B: 3/15). En consecuencia, los implementos de esta afiliación aparecen disgregados, reflejando una dispersión aleatoria y no necesariamente un patrón de concentración en determinado grupo de individuos.

Para poder definir un perfil étnico de los portadores de objetos tiwanakotas, se procedió a evaluar la deformación craneana con la posibilidad de poder definir el flujo poblacional asociado al traslado de dichos artefactos. Para esto se consideró solamente a los individuos asociados directamente con tabletas y/o tubos (tumbas individuales) y en los casos en que los restos óseos hubieran permitido su diagnóstico. En la muestra considerada solo fue posible diagnosticar tres casos con tabletas y cinco con tubos, observándose en total seis individuos con TE 
y dos ND lo que, aun siendo poco significativo, se ajusta al patrón general del sitio.

Por su parte, al contrastar los grupos A y B de Oakland en relación a las deformaciones craneanas, vemos que en ambos grupos se hacen presentes las mismas deformaciones y en proporciones similares (Tabla 10), lo cual no apoyaría la idea de Oakland de que el grupo B sería un grupo étnico diferente relacionado estrechamente con Tiwanaku. En consecuencia, se trataría de un mismo grupo étnico cuyas diferencias contextuales, relacionadas con la textilería, pueden deberse más bien a diferenciación de estatus y no necesariamente a etnicidad. Esto también se vería apoyado por el hecho de que el Grupo B, que en la fase Coyo (sector Sur) tuvo una representación de 77,7\%, en la fase Yaye (sector Norte) baja a $11,1 \%$ (Tabla 11), coincidente con la interrupción del flujo de objetos Tiwanaku, situación que, según lo indicado por la deformación craneana, no habría afectado la composición étnica del sitio (cfr. Tabla 6).

Tabla 10. Distribución de tipos deformatorios en los grupos Oakland.

\begin{tabular}{|l|c|c|}
\hline $\begin{array}{c}\text { Deformación / } \\
\text { Grupos }\end{array}$ & Grupo A & Grupo B \\
\hline $\begin{array}{l}\text { No } \\
\text { deformados }\end{array}$ & $4 / 12=33,0 \%$ & $6 / 21=28,5 \%$ \\
\hline Tabulares & $7 / 12=58,3 \%$ & $13 / 21=61,9 \%$ \\
\hline Circulares & $1 / 12=8,3 \%$ & $2 / 21=9,5 \%$ \\
\hline
\end{tabular}

Tabla 11. Distribución de tumbas de los grupos Oakland en los sectores del cementerio.

\begin{tabular}{|c|l|c|c|}
\hline $\begin{array}{c}\text { Grupo } / \\
\text { Sector }\end{array}$ & \multicolumn{1}{|c|}{ Sur-Sur } & Sur & Norte \\
\hline Grupo A & --- & $12 / 21=57.1 \%$ & $9 / 21=42.9 \%$ \\
\hline Grupo B & $4 / 36=11.1 \%$ & $28 / 36=77.7 \%$ & $4 / 36=11.1 \%$ \\
\hline
\end{tabular}

$\mathrm{Al}$ incorporar la deformación craneana observamos que no existe una distribución significativamente diferencial entre ambos grupos, lo que argumentaría a favor de una misma población biológica que está recibiendo aportes culturales foráneos, con mayor intensidad en los primeros momentos. No nos olvidemos de que la ocupación de este sitio se produciría por el 720 DC, cuando la llegada de objetos
Tiwanaku a San Pedro de Atacama se encuentra en pleno apogeo.

Si la muestra procesada por Oakland (1992) fuera realmente representativa en relación a la distribución de los grupos por sectores, y no se viera afectada por un sesgo de conservación de los textiles debido a las diferentes condiciones de preservación del terreno, tendríamos que los dos grupos se hacen presentes en los tres sectores pero con diferente comportamiento. Llevado a porcentajes proporcionales al número total de tumbas en cada sector, el grupo A (supuestamente local) muestra un incremento moderado de sur a norte $(6,9 \% ; 8,6 \%$ y $13,8 \%)$; en cambio, el grupo B (supuestamente foráneo), en el sector Sur muestra el mismo índice que el grupo A $(6,9 \%)$, aumenta fuertemente en el sector Sur $(27,8 \%)$ y baja drásticamente en el sector Norte $(6,1 \%)$.

Los tipos deformatorios circular y tabular oblicuo están escasamente representados en Coyo Oriente $(7,7 \%$ y $0,9 \%$ respectivamente), por lo que se asumen aportados por componentes exógenos a la localidad. Cocilovo y Varela, al analizar numerosos cráneos correspondientes a las diversas fases de esta localidad, determinan que la deformación circular no supera el $6 \%$ y la TO se hace presente en un 20\%, contrastando con el predominio de TE (41\%) y de ND (33\%) (Cocilovo y Varela, 2010, pp. 48 y 51$)$.

La deformación circular se asocia con poblaciones altiplánicas (Posnansky, 1914; Hjorjo y Lindh, 1947; Ruiz et al, 1984), en tanto que, en el NOA su presencia es escasa $(2,4 \%)$ (Cocilovo y Varela, 2010, p. 46). Por su parte, la deformación TO se registra con mayor frecuencia en el NOA, destacando como dominante en la Puna y en la Quebrada de Humahuaca (69\% y $64 \%$ respectivamente) en detrimento de TE (4,5\% y 26\%). En cambio, en la subárea de Valles Calchaquíes se registra un predominio de TE (82\%), seguido por los TO (14\%). En ambas subáreas los circulares no superan el 3\% (Cocilovo y Varela, 2010). Mediante este mapa de distribución de deformaciones craneanas es posible, hipotéticamente, direccionar las vinculaciones transandinas que se manifiestan en Coyo Oriente. 
La presencia de la deformación circular en Coyo Oriente es más alta que el promedio para San Pedro de Atacama (7,7\% vs 6\%), lo que se condice con el hecho de ser este sitio el que presenta la mayor cantidad de objetos Tiwanaku, respaldando la orientación de la interacción de esta localidad con la región altiplánica, no solo en cuanto al tráfico de artefactos, sino también en relación al flujo de personas. En tanto, llama la atención la casi ausencia de TO $(0,9 \%)$ en relación al promedio para San Pedro $(20 \%)$, situación que pondría en evidencia una no preferencia de vínculos con el NOA, específicamente con la Puna y la Quebrada de Humahuaca, donde este tipo de deformación es predominante. Sin embargo, esto último resulta contradictorio si consideramos los elementos Aguada presentes en el sitio. Tal vez tendríamos que poner atención en los valles Calchaquíes, ámbito de la Cultura Aguada, donde predomina la deformación TE al igual que en San Pedro de Atacama, razón por la cual, si hubiera individuos de dicho origen, no sería posible diferenciarlos de los locales a través de la deformación.

$\mathrm{Al}$ analizar estas deformaciones en relación a los géneros, observamos que, dentro del escaso número de las deformaciones, la mayor representación involucra a mujeres. En el caso de tabulares (TO), 100\%, y en el de circulares (CE y CO), 76,4\% (ver Tabla 6), lo que develaría que en este sitio hubo una marcada inmigración del contingente femenino.

Dada la aleatoria dispersión de estas deformaciones en las tumbas sanpedrinas y su combinación con otras deformaciones, es evidente que no se trata de un componente colonialista, sino que de una intrusión que se mezcla con la población local. Es probable que esta mezcla se haya producido a través de enlaces matrimoniales insertos en un sistema exogámico.

A lo dicho se suma el hecho de que en este cementerio hay cuatro mujeres que presentan infección por leishmaniasis, enfermedad endémica de las tierras bajas del NOA y del sur de Bolivia (Costa y Llagostera, 2014). Coincidentemente, una de estas mujeres (5377-80) presenta deformación circular y aparece asociada con una "tipa", dos rasgos vinculados con interacción foránea; además, es la tumba que tiene el más numeroso ajuar alfarero (20 piezas).
Como explicación a la presencia de estos individuos en San Pedro de Atacama, los autores proponen que estas mujeres serían originarias de regiones endémicas de la enfermedad al oriente de los Andes. Es posible suponer que el cambio de residencia se debiera a matrimonios exogámicos patrilocales.

No deja de ser importante el hecho de que en San Pedro de Atacama no se registran varones con esta patología, lo que significaría que varones de los lugares endémicos no llegaban a San Pedro y que tampoco los atacameńos, en sus circuitos caravaneros, alcanzaban aquellos lugares donde podrían exponerse a ser contagiados por la enfermedad. Así, habría que suponer la existencia de puntos nodales intermedios donde, además de las transacciones de trueque de bienes y de la celebración de ceremonias y protocolos de consolidación de nexos vinculantes, se llevaban a cabo pactos matrimoniales, de tal manera que, al regresar a los oasis, algunos varones traían mujeres procedentes de lejanas tierras orientales, sin que fuera necesario que ellos mismos hubieran llegado hasta esos lugares.

En un estudio sobre microdiferenciación craneométrica realizado con individuos de Solcor-3, Larache, Quitor 6, Catarpe y Coyo-3, (Costa-Junqueira et al., 1995), se encontró que la distancia entre los varones de estos cuatro sitios no era significativa, pero en cambio, la diferencia de las mujeres de Coyo-3 en comparación con las de los otros sitios es impactante por su magnitud. Frente a esto, los autores sugieren que los hombres atacameńos formaban parte de un sistema biológico integrado, el cual recibe el aporte exógeno de mujeres enmarcado en un patrón de patrilocalidad y exogamia. Esta información, por estar referida al mismo distrito de Coyo al que pertenece el sitio que estamos analizando, resulta coherente y refuerza lo planteado anteriormente.

Según Cocilovo et al. (2011), el análisis de diferenciación fenotípica entre las tres zonas del cementerio arrojó una significativa diferencia entre la zona Sur y las Sur-Sur y Norte. Igualmente, los valores de distancias D2 indican que el grupo de la zona Sur presenta las mayores distancias con respecto a los otros dos grupos. En consecuencia, habría que aceptar que en dicha zona Sur existe un componente bioantropológico introducido, el cual sería el causante de la 
diferencia detectada. Hipotéticamente, ello debería corresponder a la presencia de fenotipos foráneos. Por otra parte, en los contextos del grupo Sur se registran evidencias de una dinámica interacción con grupos vecinos, tanto del NOA como del sur de Bolivia, a través de una mayor presencia de alfarería foránea, de conchas de Strophocheilus, de tabletas y tubos Tiwanaku y de tipas. La presencia de ganchos de atalaje indica que la actividad caravanera fue el modo en que se materializó dicha interacción. La gente del sector Sur habría estado activa en momentos de una intensa dinámica de interacción transandina en la que se movían tanto objetos como personas. Esto podría justificar la diferencia bioantropológica del sector Sur en comparación con los sectores Sur-Sur y Norte.

En la fase Yaye (sector Norte) se observa una merma en la cantidad de objetos foráneos, de manera que si la presencia de tabletas y tejidos Tiwanaku fuera indicador de la intensidad de las relaciones de Coyo Oriente con el centro altiplánico, habría que asumir que hacia el 900 DC esta interacción colapsa. La fuerte caída de la presencia del caracol transandino Strophocheilus refuerza este supuesto (IR baja de $25,0 \%$ en el sector Sur a 7,6\% en el sector Norte). Sin embargo, la alfarería atípica -la que también se asume foránea- se incrementa notoriamente en esta fase, pudiendo significar que la interacción persiste pero circunscrita a un espacio más restringido. La significativa diferencia fenotípica detectada por Cocilovo et al. (2011), entre el sector Norte y el sector Sur, delataría que no solo el flujo de objetos foráneos disminuyó en la fase Yaye, sino también el flujo de gente foránea.

A diferencia de la mayoría de los sitios de los oasis de San Pedro de Atacama, los cuales vienen desde la fase Toconao o por lo menos de la fase Séquitor, Coyo Oriente no tiene antecedentes asociados con dichas fases. Se podría sostener la hipótesis de que la ocupación del sitio se habría producido en los momentos en que la fase Coyo estaba vigente en San Pedro de Atacama y habría persistido hasta la fase Yaye. Esta colonización podría estar asociada con la función que cumplían los martillos, probablemente relacionada con actividades metalurgistas específica y circunscrita al distrito de Coyo, ya que estos artefactos también se les encuentra en Coyo 3 (Costa y
Llagostera, 1994) y no en otros lugares de San Pedro de Atacama.

\section{Consideraciones finales}

Coyo Oriente, por contextos y fechas, resulta ser un efectivo referente del Período Medio en San Pedro de Atacama, puesto que la principal ocupación del sitio se adscribe a la fase Coyo, y no presenta antecedentes de la fase previa (Quitor). Se trata de un segmento poblacional que llega a colonizar el lugar con un bagaje cultural representativo de ese período. Dentro de sus contextos destaca la marcada presencia del componente Tiwanaku, especialmente a través de la parafernalia psicotrópica y la textilería, lo que no implica instalación de gente oriunda de Tiwanaku.

A pesar de que este sitio ocupa el segundo lugar en San Pedro de Atacama en cantidad de artefactos Tiwanaku, no creemos que haya existido una interacción directa entre estos dos lugares. Desde 1995 estamos insistiendo en el concepto de "red": "sistema reticular de interacción circumpuneña” (Llagostera, 1995 y 2006b). En el amplio espacio intermedio entre estas localidades existirían numerosas comunidades, varias de las cuales funcionaban como nodos de una extensa red, interactuando entre sí y articulando un flujo multidireccional por el que iban y venían los objetos. Los atacameños no necesariamente llegaban hasta los lugares de procedencia de los artefactos sino que, al igual que personas de diferentes etnias, confluían en los nodos para efectuar sus transacciones, produciéndose entrecruzamiento de artefactos. De esta manera los objetos iban pasando de unos a otros, como en un sistema de postas. Esto explicaría la heterogeneidad del componente foráneo en los contextos arqueológicos, reflejando diversas procedencias. Pero en el entramado de esta red no solo se movían objetos sino también gente, no exclusivamente de forma temporal, sino que algunos de ellos se quedaban en lugares distintos al de su origen.

El radio de esta red alcanzaría hasta Tiwanaku por el norte y se extendería hasta territorios de la Cultura Aguada por el sur, comprometiendo a todas las comunidades que habitaban el amplio espacio entre estos extremos. En el Período Medio esta red 
estuvo marcada fuertemente por la impronta Tiwanaku, ya que esta era la entidad predominante del momento; es así que los objetos Tiwanaku son los que destacan en el componente foráneo de los contextos de la fase Coyo. Dado el alto desarrollo que había alcanzado Tiwanaku en los Andes Centro Sur, sin duda esta entidad fue la más interesada en fomentar la fluidez de la red para acceder a lejanos recursos y bienes complementarios y de prestigio. Por su parte, a las comunidades del entramado les interesaba insertarse en ella para usufructuar de los beneficios de una más amplia esfera de interacción. En consecuencia la red, que ya funcionaba en el Formativo, cobró una mayor amplitud y dinamismo en el Período Medio.

Esta sofisticada red no solo involucraba tráfico de objetos domésticos -como la alfarería- sino también elementos de carácter ritual -como las tabletas- impregnados del más alto simbolismo ideológico. Es muy difícil aceptar que artefactos tan especiales como estos últimos se hayan incorporado a un simple sistema de trueque. Su movilidad en el espacio circumpuneño necesariamente tuvo que tener connotaciones socio-políticas muy especiales. Algunos bienes y objetos, como la alfarería, eran accesibles por esta vía a todos los miembros de la sociedad atacameña; en cambio otros, como tabletas y tejidos, se movían dentro de ciertas esferas, privilegiando y reforzando los estatus jerárquicos.

El manejo de esta red ha implicado una no menos compleja organización sociopolítica de las comunidades, con líderes reconocidos tanto al interior como al exterior de ellas, refrendados como interlocutores válidos para interactuar con sus pares de los nodos vecinos. Todo ello seguramente enmarcado dentro de protocolos y ceremonialismos propios de las culturas andinas. Esto no implica la constitución de élites en San Pedro de Atacama, ya que no se distinguen segmentos de la población cualitativamente disgregados del resto; solo algunos individuos destacan por portar ciertos elementos que denotan un estatus moderado sin reflejar una marcada desigualdad y mucho menos una estratificación social.

En relación al flujo genético, hemos visto que al comienzo de la ocupación de Coyo Oriente (sector Sur-Sur) hay un predominio del componente ataca- meño, luego (sector Sur) se agregaría un importante componente exógeno debido a la incorporación de gente foránea, lo que ha hecho que el perfil fenotípico del sector Sur, asociado a la fase Coyo, difiera del anterior; esto coincide también con el auge de objetos foráneos. En el sector Norte (fase Yaye), vuelve a predominar el componente atacameño, consecuentemente, con una merma del componente exógeno bioantropológico y artefactual de larga distancia (Tiwanaku).

En síntesis, el cementerio de Coyo Oriente resulta ser un excelente referente del Período Medio de San Pedro de Atacama debido a su instalación por gente ya adscrita a la fase Coyo sin vestigios de fases previas, resultando arqueológicamente en una muestra pura de dicho período. La mayor representatividad de Coyo Oriente estuvo en el sector Sur del cementerio, manifestando el máximo dinamismo y auge sociopolítico y cultural de la población que ocupó el lugar.

\section{Agradecimientos}

Por varios ańos los autores formamos parte del cuerpo académico del Instituto de Investigaciones Arqueológicas y Museo "R.P. Gustavo Le Paige s.j." de la Universidad Católica del Norte, en San Pedro de Atacama. Durante ese tiempo tuvimos la oportunidad - por la cual nos sentimos agradecidos- de estudiar las colecciones del museo. El presente trabajo es uno de los resultados de esa dedicación.

\section{Referencias citadas}

Agüero, C. (2003). Componente Tiwanaku vs componente local en los oasis de San Pedro de Atacama. En Tejiendo sueños en el Cono Sur. Textiles Andinos: Pasado, presente y futuro. Actas del Simposio ARQ 21. 51० Congreso Internacional de Americanistas, pp. 180-198.

Berenguer, J. (1984). Hallazgos La Aguada en San Pedro de Atacama, Norte de Chile. Gaceta Arqueológica Andina, 12, 12-14, Instituto Andino de Estudios Arqueológicos, Lima.

Berenguer, J., Deza, A., Roman, A. y Llagostera, A. (1986). La secuencia de Myriam Tarragó para San Pedro de Ata- 
cama: un test por termoluminiscencia. Revista Chilena de Antropologia, 5, 17-54.

Cocilovo, J., Zavattieri, M. y Costa, M. A. (1994). Biología del grupo prehistórico de Coyo Oriental (San Pedro de Atacama, norte de Chile): I Dimorfismo sexual y variación etaria. Estudios Atacameños, 11, 121-133.

Cocilovo, J. y Varela, H. (2010). La distribución de la deformación artificial del cráneo en el Área Andina Centro Sur. Relaciones de la Sociedad Argentina de Antropología, XXXV, 41-68.

Cocilovo, J., Varela, H. y Llagostera, A. (2011). Armando el rompecabezas de San Pedro de Atacama: El sitio Coyo Oriental y la Cuestión de los Sectores del Padre La Paige desde la Antropología Biológica. Revista Chilena de Antropología, 23, 149-172.

Costa-Junqueira, M. A. y Llagostera, A. (1994). Coyo-3: momentos finales del Período Medio en San Pedro de Atacama. Estudios Atacameños, 11, 73-107.

Costa, M. A. y Llagostera, A. (2014). Leishmaniasis en Coyo Oriente. Migrantes transandinos en San Pedro de Atacama. Estudios Atacameños. Arqueología y Antropologia Surandinas, 47, 5-18.

Costa, M. A., Llagostera, A. y Cocilovo, J. (2008). La deformación craneana en la población prehistórica de Coyo Oriente, San Pedro de Atacama. Estudios Atacameños. Arqueologia y Antropologia Surandinas, 36, 29-42.

Costa, M. A., Llagostera, A., Rothhammer, A. y Silva, C. (1995). Microdiferenciación craneométrica entre poblaciones agroalfareras de San Pedro de Atacama. Actas del XIII Congreso Nacional de Arqueología Chilena, Hombre y Desierto, 9(2), 27-30.

Costa, M. A., Matheson, C., Lachetta, L., Llagostera, A. y Appenzeller, O. (2009). Ancient leishmaniasis in a Highland desert of northern Chile. PLoSOne, 4(9), e6983. Epub.

Hjortsjo, C. H. y Lindh, J. (1947). Anthropological investigation of the craneal and skeletal material from Dr. Stig Ryden's archaeological expeditions to the Bolivian highlands, Appendix II. En Ryden, S. (Ed.), Archaeological Research in the Higlands of Bolivia (pp. 517-559). Göteborg: Elanders Boktrykeri Aktiebolag. Göteborg.
Ibarra, D. E. (1971). Argentina Indigena y Prehistoria Americana. Buenos Aires: TEA.

Le Paige, G. (1972-73). Tres cementerios indígenas de San Pedro de Atacama y Toconao. Actas del VI Congreso de Arqueología Chilena, pp. 163-187. Santiago.

Lessa, A. y Mendonca de Souza, S. M. F. (2006). Broken noses for the gods: ritual battles in the Atacama Desert during the Tiwanaku period. Mem, 133-138.

Llagostera, A. (1995a). El Componente Cultural Aguada en San Pedro de Atacama. Boletín del Museo Chileno de Arte Precolombino, 6, 9-34. Santiago.

Llagostera, A. (1995b). San Pedro de Atacama: Nodo de Complementariedad reticular. En La Integración Surandina Cinco Siglos después. Estudios y Debates Regionales Andinos, 91, 17-42. Centro de Estudios Regionales Andinos "Bartolomé de Las Casas". Cuzco.

Llagostera, A. (2006a). Contextualización e iconografía de las tabletas psicotrópicas tiwanaku de San Pedro de Atacama. Chungara. Revista de Antropología Chilena, 38(1), 83-111.

Llagostera, A. (2006b). San Pedro de Atacama y el sistema reticular de interacción puneña. En Esferas de interacción prehistóricas y fronteras nacionales modernas: los Andes sur centrales. Instituto de Estudios Peruanos - Institute of Andean Research. Historia Andina, 32, 303-322.

Oakland, A. (1992). Textiles and ethnicity: Tiwanaku in San Pedro de Atacama, North Chile. Latin American Antiquity, 3(4), 316-340.

Orellana, M. (1985). Relaciones Culturales entre Tiwananaku y San Pedro de Atacama. Diálogo Andino, 4, 247257. Universidad de Tarapacá, Arica.

Posnansky, A. (1914). Una Metrópoli Prehistórica en la América del Sud, tomo 1. Berlín: Dietrich Reimer (Ernst Vohsen).

Ruiz, A., Marrodán, M. D. y Puig-Samper, M. A. (1984). Cráneos normales y deformados de Tiahuanaco, Estudios de Antropología Biológica. II Coloquio de Antropologia Física Juan Comas, 449-474.

Tarragó, M. N. (1968). Secuencias Culturales de la Etapa Agroalfarera de San Pedro de Atacama (Chile). Actas y Memorias del XXXVII Congreso Internacional de Americanistas, vol. 2, pp. 119-145. Mar del Plata. 
Tarragó, M. N. (1989). Contribución al conocimiento arqueológico de las poblaciones de los oasis de San Pedro de Atacama en relación con los otros pueblos puneños, en especial, el sector septentrional del valle calchaqui. Tesis para optar al grado de Doctor en Historia. Universidad Nacional de Rosario, Argentina.

Torres-Rouff, C. y Hubbe, M. (2013). The sequence of human occupation in the Atacama oases, Chile: a radiocarbon chronology based on human skeletal remains. Latin American Antiquity, 24(3), 330-344.
Uribe, M. y Agüero, C. (2001). Alfarería, Textiles y la Integración del Norte Grande de Chile a Tiwanaku. Boletín de Arqueología PUCP, 5, 397-426.

Uribe, M., Santana-Sagredo, F., Maturana, A., Flores, S. y Agüero, C. (2016). San Pedro de Atacama y la cuestión Tiwanaku en el Norte de Chile: impresiones a partir de un clásico estudio cerámico y la evidencia bioarqueológica actual (400 - 1.000 D.C.). Chungara. Revista de Antropología Chilena, 48(2), 173-198. 